\title{
Vascularization Approaches in Tissue Engineering: Recent Developments on Evaluation Tests and Modulation
}

\author{
Soraia V. Lopes, Maurice N. Collins, Rui L. Reis, Joaquim M. Oliveira, and Joana Silva-Correia*
}

Cite This: https://doi.org/10.1021/acsabm.1c00051

Read Online

ABSTRACT: This review focuses on vascularization and strategies involved in its evaluation and modulation. Clinical issues associated with engineered tissues of an atomically relevant size that require a vascular network to supply their cells with nutrients and oxygen are analyzed in terms of vascular network formation within scaffolds, which can be produced from varying biomaterials, with the capability of connecting to the vasculature of the patient. Developing angiogenesis techniques and monitoring of angiogenesis development as well as how these methods can be further utilized to tailor vascularization within large tissue engineered constructs are also discussed. Finally, we offer a glimpse toward the future by providing an outlook for vascularization and associated emerging bioprinting concepts in tissue engineering applications.

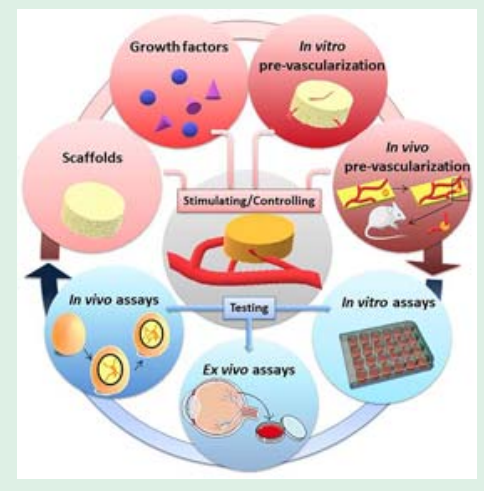

KEYWORDS: angiogenesis, vascularization, tissue engineering, tissue scaffolds, in vitro/in vivo assays

\section{INTRODUCTION}

In healthy biological systems, a constant supply of nutrients and oxygen is essential. This is achieved by the vascular system, which is formed during embryonic development and continues to develop throughout adulthood (Figure 1). ${ }^{1}$ During the natural development of the aforementioned system, there can be two defined processes: (i) vasculogenesis, regarding the formation of new blood vessels, and (ii) angiogenesis, corresponding to the development of blood vesssels from a pre-existing vascular network. ${ }^{2}$ Angiogenesis occurs in response to various distinct pro-angiogenic signals released by a tissue in need of oxygen and nutrients. Additionally, blood vessels can also naturally regress in response to a functional demand. For example, angiogenesis in the muscles is stimulated by exercise, whereas weight loss leads to capillary regression in adipose tissue. ${ }^{3}$

Abnormal angiogenesis can lead to several illnesses such as stroke, myocardial infarction, cancer, among others. Thus, understanding and controlling the angiogenic process can allow us to envision the development of novel and powerful therapeutic approaches. ${ }^{4}$ The angiogenic response can depend on the functional demand of a tissue or cell, meaning that it displays different characteristics when considering the type of tissue, individual age, and physiological/pathological states. However, the process itself is composed of four main steps (Figure 2) and it can involve several cell types, extracellular matrix (ECM) components, growth factors, and cytokines. ${ }^{4}$ First, there is vascular sprouting (Figure $2 b, c$ ), where the endothelial cells leave their quiescent behavior in response to pro-angiogenic signals and start to proliferate. These signals include vascular endothelial growth factor (VEGF), fibroblast growth factors (FGF), angiopoietins, and hypoxia inducible factors, and they can either be released by a tissue in demand of oxygen and nutrients or by injured cells. Second, there is tubule morphogenesis (Figure 2d), where a lumen is developed with the help of fibroblasts secreting tubulogenesis-stimulating molecules and ECM molecules. The third step corresponds to the adaptation to tissue needs (Figure 2e) where the newly formed vessel sprouts either regress or stabilize. This is defined once more by the tissue or cell that initiated the angiogenic process. If there is a sudden loss of the pro-angiogenic factors and there is no blood flowing through the new vessels, the tubes regress and undergo apoptosis. Conversely, a mixture of a specific cocktail of angiogenic factors such as VEGF, platelet-derived growth factor (PDGF), Ang-1, Ang-2, and blood flow stabilizes the new endothelial tubes. The last step corresponds to vessel stabilization (Figure $2 \mathrm{a}-\mathrm{e})$ where the proliferative state of the endothelial cells is replaced by a quiescent one; blood flow is adjusted in the new sprouts with adhesion between adjacent cells and to the ECM

Received: January 15, 2021

Accepted: March 18, 2021 


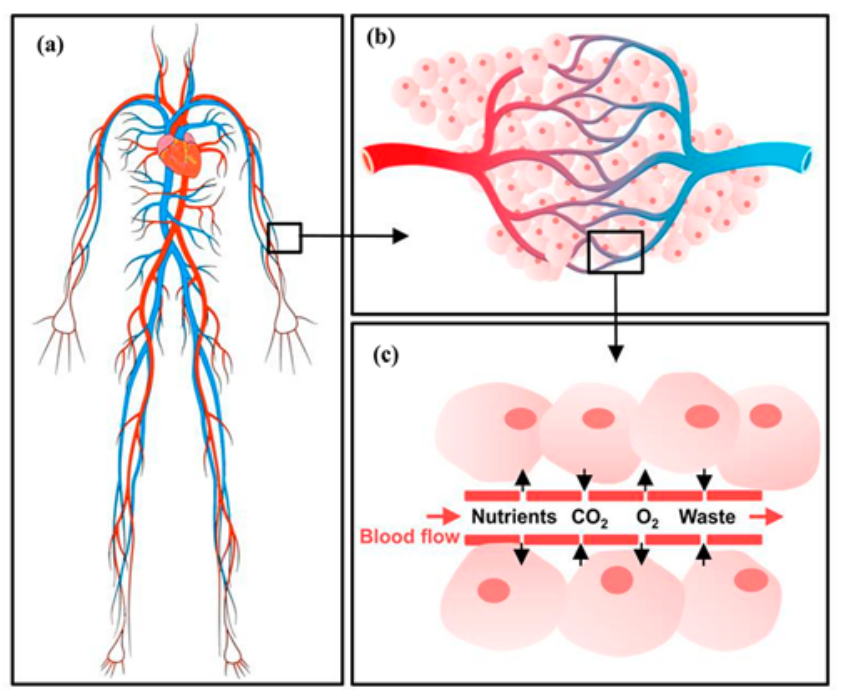

Figure 1. Simplified version of the cardiovascular system (not to scale). (a) Cardiovascular system, which includes the heart and blood vessels, is responsible for not only carrying hormones, which are elements of the immune system but also enabling cells to exchange nutrients, waste and gases, and other molecules all through the body. (b) Arterioles are connected to the venules by capillaries. (c) Blood flowing from oxygenated arterioles into capillaries enables solute exchange at tissue interface: nutrients and oxygen are delivered to the tissue, and $\mathrm{CO}_{2}$ and other metabolic byproducts are taken up by blood. Thus, a strong and functional capillary network linked to the circulatory system is essential for regenerative purposes. Reproduced with permission from ref 1 . Copyright 2019, Elsevier.

re-established. PDGF, shingosine 1, Ang-1, and transforming growth factor $\beta$ (TGF- $\beta$ ), along with the ECM and the blood flow, have been acknowledged as important contributors to this stabilization step. ${ }^{4,5}$

In tissue engineering (TE), the goal is to replace damaged biological tissues with substitutes that mimic their morphology and function. Thus, proper vascularization of those substitutes is essential upon implantation into the patient, especially in large-size grafts. In small implants, the diffusion of nutrients and oxygen from the pre-existing vasculature is enough to maintain cell viability. However, in larger implants, this diffusion only reaches the outer cell layers leading to the cell death in the core. In fact, a healthy distance between a blood supply and living cells should be around $200 \mu \mathrm{m} .{ }^{2}$ Vascularization of implanted tissues not only allows the supply of nutrients and oxygen, and the exchange of metabolites, but also enables the presence of highly specialized cells within the graft, which contributes to tissue regeneration and remodeling. ${ }^{6}$ There are several approaches that can be used to understand and monitor the angiogenic process and to better foster the integration of blood supply in larger constructs. Such advanced approaches will be further discussed throughout this review.

Angiogenesis has been the subject of previous reviews focusing on wound models, ${ }^{7}$ functionalized biomaterials, ${ }^{8}$ tumors, ${ }^{9}$ mitochondria ${ }^{10}$ and growth factors, ${ }^{11}$ ECM influences on blood vessel formation, ${ }^{12}$ and its role in TE strategies. ${ }^{13}$ However, this review provides an in-depth discussion on the biomaterials engineering aspects of angiogenesis. In addition, the recent biomaterial developments that are leading to new strategies for vasculature creation within tissue scaffolds are also overviewed. The role of angiogenesis in vascularization of

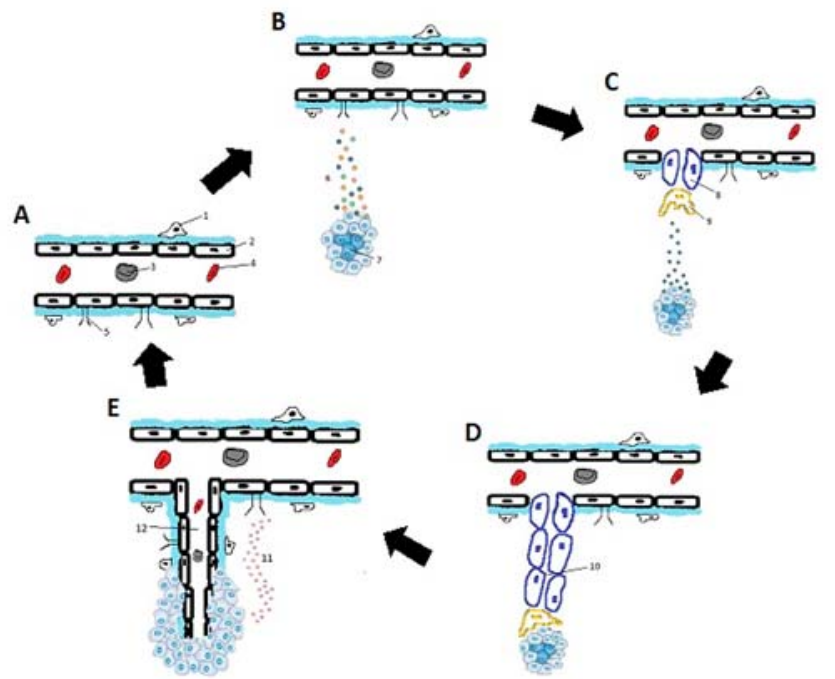

Figure 2. Schematic representation of the angiogenic process. (A) Stable blood vessel. (B, C) Vascular sprouting. The release of proangiogenic signals from a tissue in need of oxygen and nutrients is recognized by the receptors present in the vessel. Pericytes surrounding the endothelial cells detach and degrade the basement membranes by expressing matrix metalloproteases. Fibroblasts produce a provisional extracellular matrix for the new vessel sprout. The bud of the sprout includes the tip cells, with ability to migrate, and stalk cells, which proliferate and contribute to the elongation of the vessel sprout. (D) Tubule morphogenesis. The endothelial cells proliferate out of the parent vessels and acquire a lumen via pinocytosis of vacuoles formed by the endothelial and stalk cells. These vacuoles merge and span the multiple endothelial cells. Fibroblast produces tubulogenesis-stimulating molecules inducing tube formation. (E) Adaptation to tissue needs and stabilization/ maturation. Once the new vessel reaches the tissue in need, there is vascular regression, and the new vessel stabilizes and matures. The release of stabilizing signals along with the presence of blood flow within the new vessel triggers the stabilization and maturation of the sprout. The endothelium returns to its quiescent behavior, blood flow is directed to the new vessel and adhesion between adjacent cells and also between the cells and the extracellular matrix is re-established. Pericytes are recruited to the vessel, matrix degradation is inhibited, and a new basement membrane is produced for the new vessel. Pericytes and extracellular matrix are also responsible for inhibiting endothelial migration and proliferation and provide pro-survival signals to the endothelial cells. 1, pericyte; 2, endothelial cell (EC); 3, leukocyte; 4, erythrocyte; 5, EC receptor; 6, pro-angiogenic paracrine signals; 7 , tissue in need of oxygen and nutrients; 8 , stalk cell; 9, tip cell; 10, lumen formation; 11, stabilizing signals; 12, new mature vessel.

varying tissue constructs (e.g., scaffolds, cell sheets, 2D patterning) as well as biomaterial, growth factor influences, and in situ strategies are also discussed herein. This review also covers the latest advancements in angiogenesis assessment techniques both in vitro and in vivo, enabling an evaluation of the behavior of scaffolds before implantation in its final target tissue. Preclinical and post clinical (where available) data are discussed. These reveal the importance of developing novel approaches by addressing the angiogenic potential. From using sequential delivery of growth factors as a potential treatment for ischemia, ${ }^{14}$ to the development of biomimetic induced membranes for bone defect repair, ${ }^{15}$ these strategies show how relevant it is to understand this concept and how it can be used for regeneration and tissue engineering purposes. Finally, the details on how growth factors, scaffold design, cell-based 


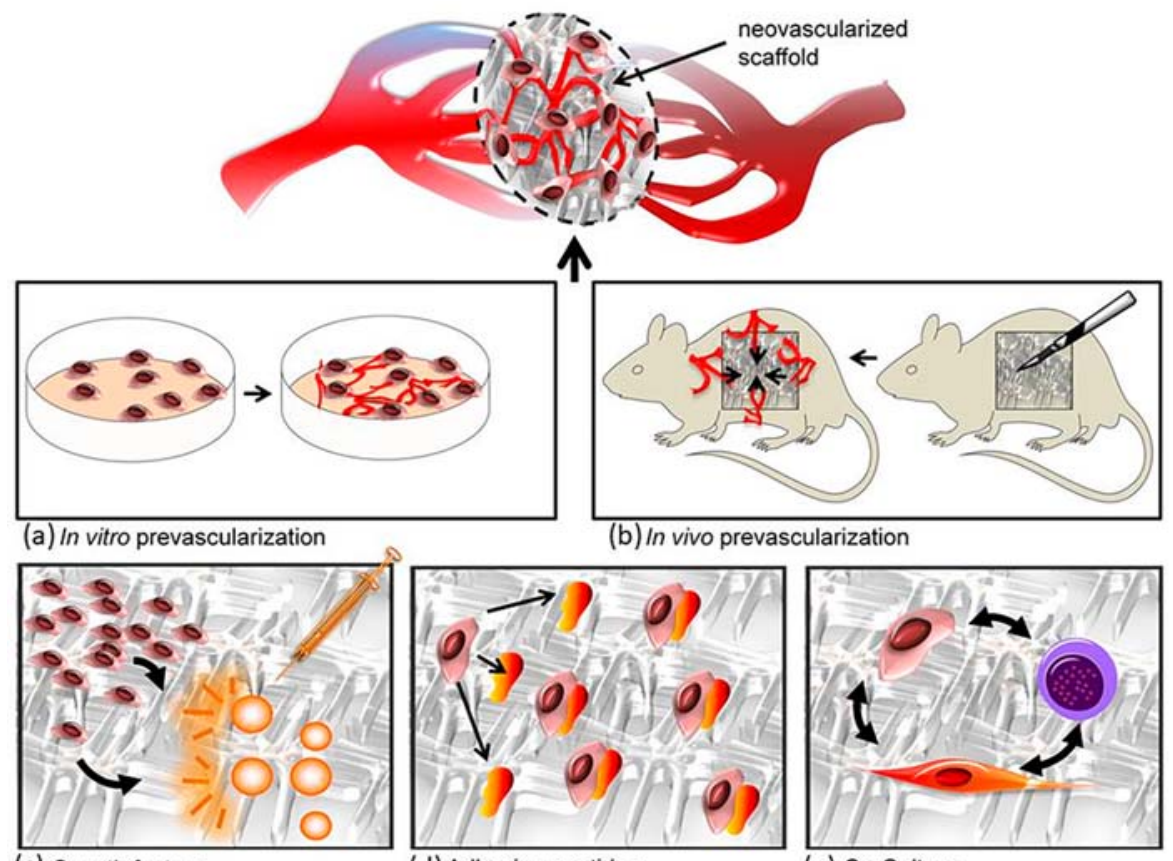

(c) Growth factors

(d) Adhesion peptides

(e) Co-Culture

Figure 3. Five different approaches to stimulate angiogenesis: $(a, b)$ in vitro and in vivo prevascularization strategies; (c) by means of adding growth factors; (d) by means of adding adhesion peptides; (e) co-culturing different cell types. Reproduced with permission from ref 13 . Copyright 2010 , Elsevier.

strategies, and molecule immobilization techniques can infer the benefits to angiogenesis and subsequent vascularization are addressed. Vascularization in tissue engineering is still a limitation due to nutrient and oxygen diffusion, which subsequently impacts the ability to develop constructs with clinically relevant dimensions and their integration in vivo. Thus, understanding and developing ways to improve the functionalization of the materials used is crucial.

\section{VASCULARIZATION APPROACHES IN TISSUE ENGINEERED CONSTRUCTS}

The vascularization of tissue engineered constructs is essential for their successful implantation and functionality in vivo. Upon implantation of the construct, oxygen and nutrients diffuse passively from surrounding blood vessels, providing a rich environment to maintain viability of small grafts. However, in bigger constructs, this passive diffusion of oxygen and nutrients does not reach their core, and this can lead to a hypoxic environment that eventually results in apoptosis. ${ }^{16}$

2.1. Classical Strategies. A classical strategy focuses on the stimulation of vascularization within the tissue construct, and this is achieved through optimization of scaffold materials or by using growth factor delivery systems (Figure 3). ${ }^{16,17}$ Scaffolds can be combined with differing growth factors, allowing cell attachment and the creation of a 3D environment for cell-to-cell communication, thus enabling angiogenesis to occur after implantation. Since the materials used for scaffold production will interact with vascular cells, their selection is crucial and largely dictated by implantation location. These materials should be biocompatible, biodegradable, nontoxic, and mimic the local ECM. ${ }^{18,19}$ Density, stiffness, viscoelasticity, degradation, and the presence of integrin-binding motifs are some of the ECM features that must be considered. ${ }^{19}$

2.1.1. Optimization of Scaffold Materials. Designing angiogenic biomaterials that enable vascularization and cell recruitment is especially important for the formation of revascularized tissue into the implants. Strategies for the development of such biomaterials include tailoring their physicochemical properties and pore architecture. ${ }^{20}$ Surface chemistry has been described to influence angiogenesis as it is recognized by the surrounding cells. The addition of molecules such as RGD and YIGSR peptides to metallic surfaces have been explored to promote human umbilical vein endothelial cells (HUVECs) adhesion in culture. ${ }^{21}$ Fibronectin is involved in integrin signaling of endothelial cells and coating with this material has been performed. ${ }^{22}$ Nanopatterning using fibronectin was also explored ${ }^{23}$ revealing an influence on proliferation of endothelial cells depending on its density, adhesion size, and distance between fibronectin islands. Surface topography, such as pillars, pits, grooves, tubes, fibers, etc., can also be an important cue to promote angiogenesis. Bettinger et al. ${ }^{24}$ used ridge-groove grating substrates that resulted in enhanced tubular formation and organization of endothelial progenitor cells. Kim et al. ${ }^{25}$ showed that different surface patterns created using nanotopography can stimulate the secretion of different angiogenic molecules. Stiffness is another biomaterial property that can influence the formation of vascular networks. For example, endothelial cells cultured on stiff type-I collagen hydrogels produced more actin stress fibers when compared to ones cultured on soft type-I collagen hydrogels. ${ }^{26}$ Another example of how stiffness can be used to modulate endothelial cells is the work developed by Santos et al., ${ }^{27}$ where HUVECs cultured on collagen-coated polyacrylamide (PAAm) hydrogels with different stiffness levels influenced the expression of pro-angiogenic and osteogenic factors. Degradation rate of the biomaterial used is also a particularly important cue for cellular behavior. Fibrin gel matrices, for example, have been developed with covalently bonded VEGF variant. Ehrbar et al. ${ }^{28}$ showed a controlled VEGF variant release upon cell matrix degradation, giving rise 
to a superior neovessel formation. Finally, the pore architecture can also be tuned to maximize vascularization of constructs. Calcium phosphate $(\mathrm{CaP})$ was used to prepare particles with several pore sizes, and their ability to induce angiogenesis was assessed in a critical-sized cranial defect in mice. Bigger pore sizes showed higher functional capillary density. ${ }^{29}$ Porous hydrogels have also been studied to improve vessel formation. PEG hydrogels with different pore sizes were developed and tissue in growth was evaluated in $3 \mathrm{D}$ cell culture and rodent models. Smaller pores lead to lower vessel invasion, whereas bigger pores promoted a deeper vascular ingrowth. ${ }^{30}$ Besides the size of the pore itself, the porosity in the scaffold is also relevant for vessel formation. Walthers et al. ${ }^{31}$ developed electrospun scaffolds with a range of porosity from 15-25\% and showed significantly higher blood vessel infiltration in higher porosity range. Pore interconnection should also be considered, as it determines the area and number of blood vessels in the construct. CaP scaffolds with different interconnection sizes and similar pore sizes were evaluated in a rabbit femoral condyle, showing significantly improved revascularization for higher interconnection size values. ${ }^{32}$ Somo et al. ${ }^{33}$ developed PEG hydrogels with controlled pore interconnectivity by sacrificial poly(methyl methacrylate) (PMMA) microspheres. Higher pore interconnectivity led to complete vascularization within 3 weeks, whereas lower pore interconnectivity showed limited vascularization. The biomaterial itself can also influence vascularization. Several synthetic polymers have been developed for this purpose. Polyglycolic acid (PGA), for example, is a biodegradable polymer that promotes neovascularization. $\mathrm{Li}$ et al. ${ }^{34}$ have shown that vascularization of an islet graft can be greatly improved by culturing endothelial cells on a PGA scaffold. Poly lactic acid (PLA)-derived materials are also frequently used. For example, Caldara et al. $^{35}$ demonstrated the angiogenic potential of poly-L-lactid acid (PLLA) by implanting PLLA disks into dorsal subcutis of mice. Some nondegradable synthetic polymers have also been used for tissue vascularization. For example, vascularization potential of different polyurethane scaffolds was studied by Laschke et al. ${ }^{36}$ However, synthetic materials present some disadvantages, namely the absence of bioactive molecules within their molecular structure. ${ }^{18}$

Natural polymers have also been explored. Collagen, a main component of the ECM, offers porosity, permeability, biocompatibility, and biodegradability. ${ }^{37}$ Chen et al. ${ }^{14}$ studied the performance of a three-dimensional (3D) collagen-based scaffold by assessing its biological responses in vitro and in vivo. Besides enabling cell adhesion, promoting cell growth and osteogenic differentiation of rat mesenchymal stem cells (MSCs) in vitro, this scaffold also demonstrated an ability to recruit and differentiate MSCs from subcutaneous tissue, and it enabled angiogenesis. Chan et al. ${ }^{38}$ demonstrated the vascularization potential of a porous $3 \mathrm{D}$ collagen scaffold implanted in vivo. Fibrin is formed during blood clotting and provides a suitable environment for angiogenesis. However, because of its poor mechanical properties and fast degradability, fibrin is mainly used as a composite. ${ }^{39,40}$ Urech et al. ${ }^{41}$ used a fibrin matrix to show that its features could be tailored to become biologically stimulating and promote angiogenesis. Jiang et al. $^{42}$ used porous poly(ethylene glycol) (PEG) hydrogels loaded with fibrin and demonstrated fibrin's ability to induce vascularization by using the PEG hydrogels alone as a control. Elastin is a protein from the connective tissue and has been greatly investigated for vessel formation. Schmidt et al. $^{43}$ used arteriovenous (AV) loops loaded with collagenelastin and collagen-glycosaminoglycan scaffolds and showed homogeneous vessel formation. Silk fibroin has also been described for tissue vascularization. Unger et al. ${ }^{44}$ developed microcapillary-like structures formed by endothelial cells, osteoblast cells, and silk fibroin scaffolds; they were implanted in immune-deficient mice. The in vitro preformed microcapillaries were not only anastomosed to the host vasculature but also stimulated the rapid growth of host capillaries into and within the implanted material. $\mathrm{Li}$ et al. $^{45}$ investigated the neovascularization and biodegradation of silk fibroin scaffolds in vivo. They observed an enhancement in vascularization after 20 days of implantation. Alginate is a polysaccharide from brown seaweed and bacteria. Alginate hydrogels are highly hydrated, and this promotes cell viability, but they lack attachment sites for vascular cells. ${ }^{46}$ Therefore, the possibility to cross-link peptides and incorporate angiogenic factors and adsorbed proteins has been studied. Nemati et al. ${ }^{47}$ investigated how alginate-gelatin encapsulation affected the angiogenic behavior of human endothelial cells. In vitro, the authors studied the expression of specific genes that were correlated with angiogenesis in endothelial cells and in vivo, injection of the microcapsules into muscular tissue of mice was performed to evaluate the angiogenic capacity. The results obtained suggested that the alginate-gelatin capsules can induce an angiogenic response in vivo and in vitro. GerechtNir et al. $^{48}$ have shown that the pores present in alginate scaffolds induce vasculogenesis in human embryoid bodies (hEBs). Chitosan is a carbohydrate biopolymer used in TE due to its biocompatibility, biodegradability, nontoxicity, and nonimmunogenicity. ${ }^{49}$ Recently, Hsieh et al. ${ }^{50}$ developed a chitosan-fibrin (CF)-based self-healing hydrogel that enables the formation of capillary-like structures when vascular endothelial cells were seeded, and promotes angiogenesis when injected in the perivitelline space of zebrafish. Malafaya et al. $^{51}$ demonstrated that chitosan scaffolds produced by the particle aggregation method promoted neovascularization, even in early stages of implantation. Hyaluronic acid (HA) is a nonsulfated glycosaminoglycan present in connective, epithelial, and neural tissues. ${ }^{52}$ Silva et al. ${ }^{52}$ developed gellangum (GG)-HA spongy-like hydrogels and implanted them in mice, promoting neovascularization. Kenar et al. ${ }^{53}$ produced a xeno-free, collagen/hyaluronic acid-based poly(L-lactide-co- $\varepsilon$ caprolactone) (PLC/COL/HA) microfibrous scaffold by electrospinning and, in coculture with human umbilical vein endothelial cells, it promoted vessel formation.

2.1.2. Growth Factors/RNAs Delivery Systems. The delivery of growth factors and RNAs has also been used to promote the angiogenic process. Song et al. ${ }^{54}$ used a heparinized decellularized adipose tissue (Hep-DAT) as a delivery system of vascular endothelial growth factor (VEGF) to study its vascularization potential. Human bone marrow stromal cells (hBMSCs), seeded on this system, differentiated into endothelial cells and promoted the formation of a vascular network. Murali et al. ${ }^{55}$ developed a collagen-poly(dialdehyde) guar gum-based hybrid porous scaffolds loaded with platelet derived growth factor, which led to a higher cellular and vascular response once implanted. Gümüşderelioğlu et al. ${ }^{56}$ immobilized it onto poly(2-hydroxyethyl methacrylate)-based bone scaffolds. Angiopoietin-4 improved sprout formation, which, together with VEGF (added to the scaffolds), promoted vascularization. Zhang et al. ${ }^{57}$ developed angiogenic micro- 
carriers composed of sphingosine-1-phosphate (S1P) loaded into mesoporous silica nanoparticles (MSNs), subsequently embedded into porous nanofibrous poly-L-lactide (PLLA) scaffold, which increased blood vessel formation. Li et al. ${ }^{58}$ enhanced miR-26a by developing a miRNA enhancer delivery system, which led to increased vascularization and complete repair of the critical-size calvarial bone defect in mice. Nelson et al. ${ }^{59}$ developed a scaffold loaded with nanoparticles containing siRNA. They show that this platform is highly versatile for siRNA delivery in vitro or in vivo and leads to increased vasculature in the scaffold. Nakasa et al. ${ }^{60}$ studied the potential of local injection of double-stranded miR-1, miR-133, and miR-206 to regenerate rat skeletal muscle injury and observed an increase in neovascularization after injection. Devalliere et al. ${ }^{61}$ developed an approach to make endothelial cells more sensitive to the endogenous growth factors upon implantation. Biodegradable PLGA polymer nanoparticles were synthesized, loaded with miR-132, and coated with cyclic RGD (cRGD) peptides that target an integrin produced by the cultured human umbilical vein endothelial cells (HUVECs). The nanoparticles slowly released RNA for several weeks, leading to a 2 -fold increase in the microvessel network and a higher number of mural cell-invested vessels.

These angiogenic approaches present some disadvantages, particularly for vascularization of bigger constructs. This is due to the fact that on average, the growth rate of a microvessel is approximately $5 \mu \mathrm{m} / \mathrm{h}$, which implies that the cells within the core of the implant will be hypoxic for a long period of time, eventually leading to tissue loss. ${ }^{16}$

2.2. Prevascularization. A new approach called prevascularization has been developed to overcome this issue. This concept focuses on supplying the tissue constructs with a preformed vascular network before their implantation in vivo so that, once implanted, the network can be rapidly perfused with blood by either fusing it with the surrounding host blood vessels, inosculation, or by surgical anastomosis. ${ }^{16}$ There are in vitro and in vivo approaches to prevascularization.

2.2.1. In Vitro Approaches. Cell seeding is an in vitro approach that involves the seeding of vessel-forming cells on the scaffolds before implantation. These scaffolds can be synthetic or based on natural decellularized matrix, which present the advantage of providing the ideal 3D template for the cells. Endothelial cells have been the main source of cells for this approach because they rapidly assemble into immature vessels once exposed to different biomaterials, and, after implantation, blood starts flowing within the first 10 days. ${ }^{16}$ Some disadvantages of the cell-seeding approach not only include difficult and time-consuming harvesting and cultivation processes but also the fact that the quality and number of the cells isolated, and seeding strategy influences its safety and success. Additionally, there needs to be a balance regarding the amount of cells that are seeded into the scaffolds, as too many significantly decrease vascularization even causing them to regress. Another in vitro approach involves the development of spheroids. These are clusters of cells, frequently used in oncology, drug discovery, and toxicity as it is beneficial from a biomimicry standpoint to utilize a $3 \mathrm{D}$ arrangement of cells. Within the spheroid, cells have a higher cell-to-cell and cellmatrix interaction similar to in vivo conditions of a physiological tissue. ${ }^{62}$ There are several approaches to generate these spheroids and there also different types of cells that can be used. Spheroids can be implanted once prevascularized with studies showing that connections between the host blood vessels and the vessels within the spheroid can be established. This allows the rapid initiation of blood perfusion. ${ }^{63,64}$ Lastly, cell sheet technology is based on the lack of a scaffold to culture cells. That technique has been used to promote the survival of skin flaps, showing a higher blood perfusion once implanted in vivo ${ }^{65}$ and for cardiac remodeling, with stimulation of neovascularization and cardiomyocyte proliferation, ${ }^{66}$ and will be further discussed in section 4 .

2.2.2. In Vivo Approaches. In in situ approaches, the body is used as a bioreactor to promote the formation of new functional microvessels within the scaffolds. This approach involves the introduction of a scaffold into an easily accessible and well-vascularized tissue of the body. Over time, an angiogenic response is induced leading to a random growth of new vessels from the host vasculature. Then the scaffold is removed and transferred to the target site and the blood starts flowing into the newly formed vessels of the scaffold via inosculation. A disadvantage of this process is the need of at least three surgical interventions (the first introduction of the scaffold for prevascularization, the surgical removal of the prevascularized scaffold and finally the implantation into the target site). Additionally, it is a time-consuming process, and the success of connecting the preformed vessels of the scaffold and the host vessels upon implantation into the target site is dependent on their growth after final implantation. Thus, an immediate blood perfusion is difficult to achieve. To overcome this issue, methods have been developed to surgically unite the vessels from the scaffold and the host. ${ }^{16}$ The flap technique is focused on the implantation of a scaffold into a muscle flap to promote its neovascularization from the surrounding tissue. Then the prevascularized scaffold is transferred to the target site, and the newly formed vessels and the host vessels are surgically anastomosed. A major advantage of this technique is the immediate perfusion of the scaffold after final implantation. However, tissue loss can occur, and optimization of the materials and growth factor doses used for the prevascularization step is needed. ${ }^{16}$ The arteriovenous (AV)-loop technique takes advantage of the spontaneous sprouting of vessels generated by an arteriovenous fistula shaped as a loop. A polycarbonate growth chamber is used to place the loop, along with a suitable ECM, allowing prevascularization. The construct is then implanted into the target site and surgically anastomosed to the host vasculature. The lack of major tissue loss and deformation is an advantage of this technique compared to the flap technique. ${ }^{16}$

2.2.3. Other Approaches. Microfabrication technologies and microfluidic systems have also been developed for vascularization. Creating hollow microchannels in the tissue constructs can be achieved through microfabrication. This can be produced using sacrificial materials that provide shape to the vessels. This prefabrication of vessels into the scaffolds can improve the cell viability upon perfusion. ${ }^{67,68}$ For example, a glucose-sensitive hydrogel that can be removed by addition of cell culture medium was used as a sacrificial material to introduce vascularity in constructs. ${ }^{69}$ Another way to achieve hollow microchannels is by decellularization of organs and tissues. $^{70,71}$ Microfluidic systems are focused on the controlled formation of branches within hydrogels, which can later be seeded with ECs through perfusion. A major advantage of this method is improved cell viability due to continuous flow of oxygen and nutrients and removal of waste products. A drawback of these systems is the lack of similarity to the physiological environment. ${ }^{16}$ 
Table 1. Principal In Vitro, Ex Vivo, and In Vivo Angiogenesis Assays and Their Main Advantages and Disadvantages ${ }^{a}$

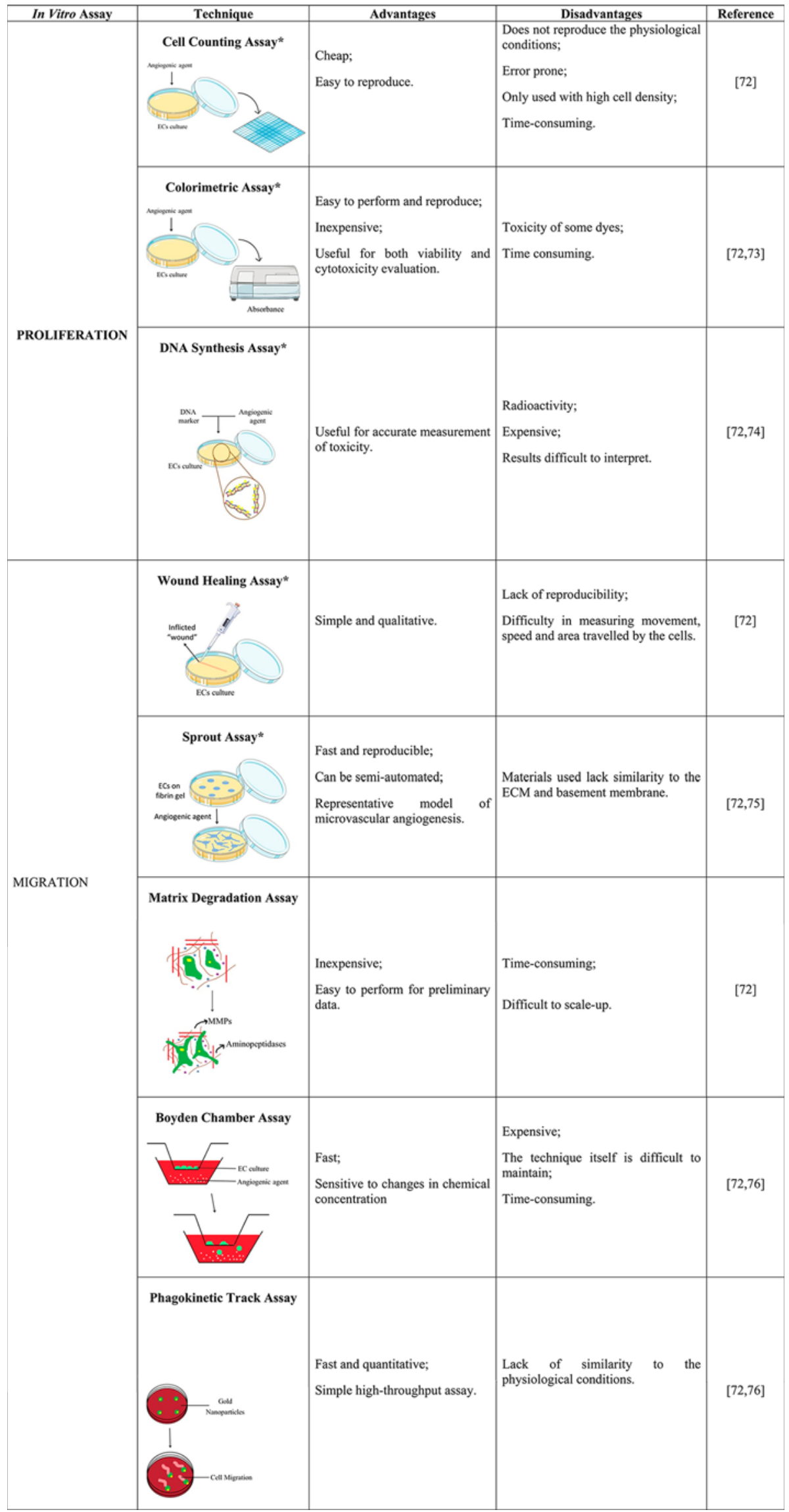




\section{Table 1. continued}

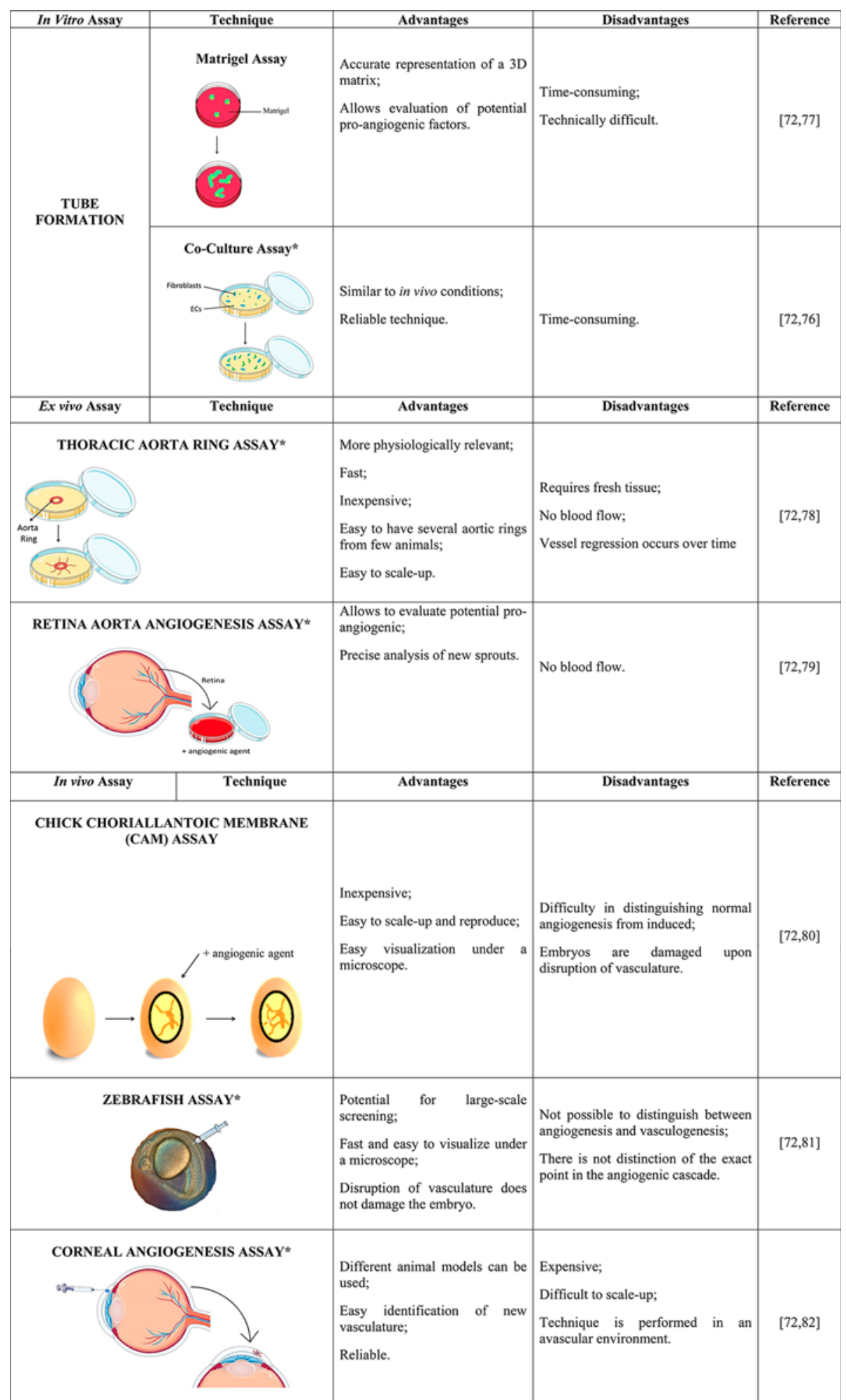


Table 1. continued

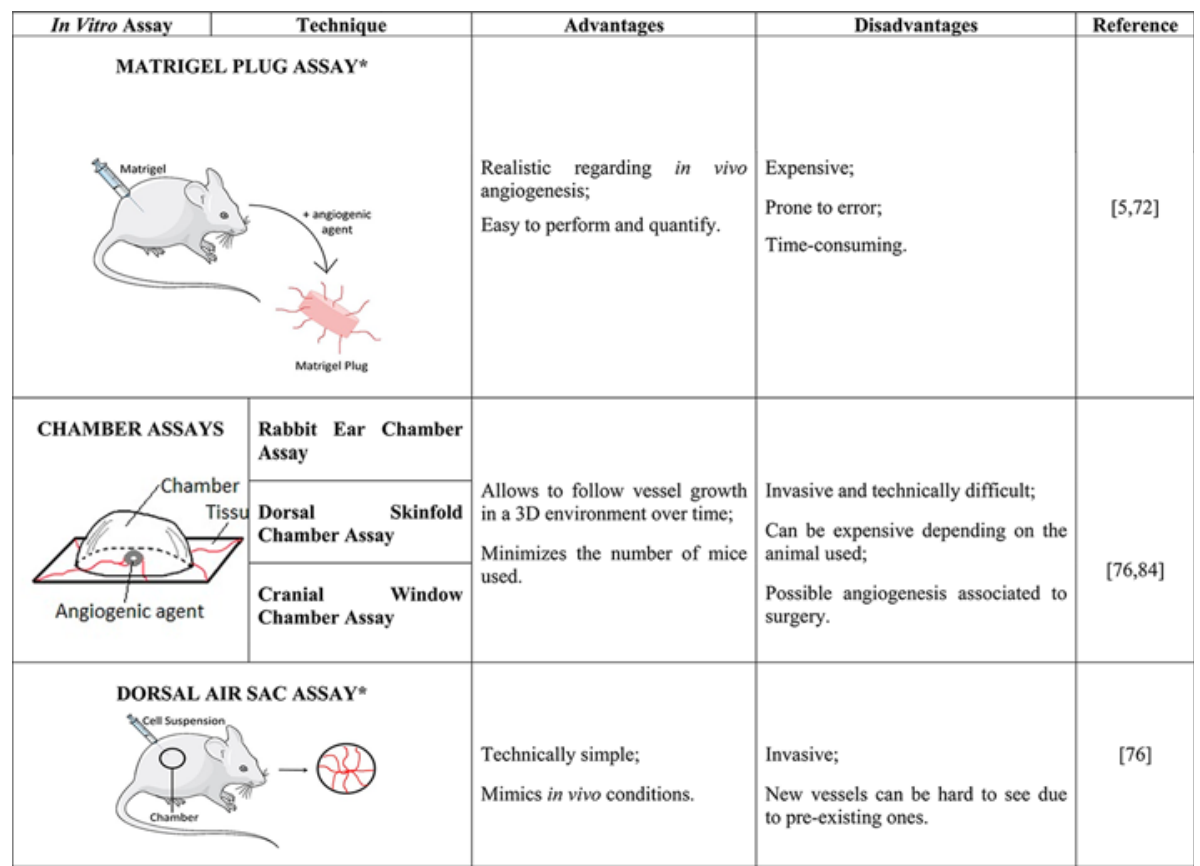

${ }^{a}$ Representation of the techniques identified by $*$ were created using images from Smart Servier (https://smart.servier.com/), licensed under CC BY 3.0 (http://creativecommons.org/licenses/by/3.0/).

Microcontact imprinting is a $2 \mathrm{D}$ patterning technique that can introduce patterns of adhesive proteins on noncelladhesive substrates, which will then allow the migration and sprouting of these capillary-patterned cells into the hydrogels. ${ }^{67}$ Wong et al. ${ }^{71}$ have shown that a vascular-branching pattern can be transferred using this technique. Photolithography is based on the generation of specific patterns onto a photomask, which is positioned on top of photo-crosslinkable biomaterials. Only the areas exposed to light will be cross-linked; therefore, remaining material can be washed away, thus creating organized microchannels. ${ }^{67} 3 \mathrm{D}$ bioprinting is another option to create a vascular network. It involves the fabrication of scaffolds and the precise placement cells into a predetermined position. ${ }^{16}$ Contractible endothelialized myocardium can be generated by seeding cardiomyocytes into 3D bioprinted microfibers and ECs. ${ }^{72}$ Some of these techniques for vascularization in TE will be further explored throughout this review.

\section{ASSESSING THE ANGIOGENIC RESPONSE}

The more frequently used angiogenic assays can be divided into three major groups: in vitro, ex vivo, and in vivo, and these are summarized in Table 1.

3.1. In Vitro Assays. These assays are used to study the mechanistic of angiogenesis. The majority of these assays are performed using ECs such as bovine aortic endothelial cells (BAECs), human umbilical vein endothelial cells (HUVECs), or human dermal microvascular endothelial cells (HDMECs). These cells are heterogeneous, which in turn can lead to different angiogenic responses. Together with the lack of proximity to the physiological environment, the results obtained by using these assays can sometimes be inconclusive. Thus, these assays are usually used to obtain some preliminary results regarding the potential of pro- or antiangiogenic agents. $^{73}$
3.1.1. Proliferation Assays. Assessing cell proliferation in angiogenesis can lead to two results: that is, a pro-angiogenic environment will lead to a low basal rate of vessel formation; an antiangiogenic environment will lead to a high basal rate of vessel formation. Some of the techniques used for this assay are cell counting of ECs. Cells are labeled and subjected to a angiogenic agent. Counting is usually performed using a hemocytometer and a light microscope, making it a cheaper and easily reproducible assay. However, the state of ECs cells in vitro differs from their state in vivo. In physiological conditions, ECs are predominantly in a quiescent state, whereas in vitro, these cells tend to be in a proliferative state. The use of a hemocytometer is prone to sampling error and can only be used with a high density of cells. Not to mention that it is time-consuming. ${ }^{3 /}$ Colorimetric assays can also be used. Here, a biomolecule will be broken down by the ECs, and the byproduct produced will be collected and directly correlated with the EC population over time. A biomolecule frequently used is 3-(4,5-dimethylthiazol-2-yl)-2,5-diphenyltetrazolium bromide (MTT), which is processed by the mitochondria in living cells and can be quantified using a spectrophotometer. Thus, a faster MTT reduction over time can be correlated to a growing cell population. Although this is an easy assay to be performed, it presents some disadvantages such as the fact that the cell metabolism can be altered by the angiogenic agents in question and that a possible apoptotic process can occur due to that metabolic alteration or due to a possible cytotoxicity of the agent in question. ${ }^{73,74}$ DNA synthesis assays are also an option to evaluate cell proliferation. Tritiated thymidine $(3 \mathrm{H})$ or bromodeoxyuridine (BrdU) will be introduced into the environment and during rapid mitosis and consequent synthesis of new DNA in proliferative cells. Either by evaluating the level of radioactivity brought by the tritiated thymidine or by immunohistochemical detection of BrdU, cell proliferation can be inferred. The use of tritiated thymidine presents an obvious disadvantage due to its 
radioactivity, whereas the use of BrdU can be expensive while providing results that can be difficult to interpret. ${ }^{73,75}$ Therefore, these assays should be complemented with other assays to obtain more valuable information.

3.1.2. Migration Assays. Migration assays tend to focus on understanding the movement of ECs when exposed to certain biomolecules. This can be achieved by evaluating wound healing potential. ECs are cultured to form a confluent monolayer, which is then "wounded". The damage will be repaired by the proliferation and migration of the surrounding cells. Usually, the proliferative process is eliminated by the addition of a specific biomolecule to focus the study on the migration potential. A disadvantage of this assay is the lack of reproducibility regarding the initial confluency of cells and the inherent difficulty in measuring movement, speed, and area traveled by the cells. ${ }^{73}$ Another way to study migration is by looking at the sprouting potential. HDMECs suspended in fibrin cells are subjected to angiogenic growth factors and the number of new sprouts and their respective length are evaluated microscopically. In this assay, a major disadvantage is the lack of similarity to the ECM and the basement membrane of the materials used. ${ }^{73,76}$ Matrix degradation can also be analyzed, as the basement membrane is disrupted during the formation of new blood vessels. Degradation of laminin-rich basement membrane and proteolysis of the collagen-rich ECM occurs, thus leading to the release of proteases such as matrix metalloproteinases (MMPs) and aminopeptides. The zymogen assay, for example, is composed of an artificial matrix, which will suffer the effect of proteases harvested from the ECs. This is a relatively inexpensive method that offers basic understanding regarding the activity of MMPs. However, it is time-consuming, and its preparation for multiple tests is difficult. ${ }^{73}$ The directionality of the cell migration can also be assessed using a modified Boyden chamber assay. The chamber is divided in two with a filter in the center that allows migration; ECs are on one-half of the chamber and the biomolecule under study is placed on the other half. The ECs will migrate in response to the chemical signal, the membrane will be dyed, and the number of cells that went through it can be counted. This is also a quick method to perform, and its sensitivity to alterations in chemical concentrations is also an advantage. On the other hand, the filters used can be expensive due to their coating with matrix proteins. $^{73,77}$ Phagokinetic track assays are also used to quantify ECs migration. A substrate covered with gold nanoparticles is used to place the ECs and a chemical stimulus is added. The movement of the cells will be engraved in the colloidal gold, which can be used to study their direction and total movement. A major disadvantage of this method is its lack of similarity to physiological conditions. ${ }^{73,77}$

3.1.3. Tube Formation Assays. These assays focus on the step of tubulogenesis, which allows the connection between new and existing vessels. Matrigel assays are a way to evaluate this process. ECs are placed on Matrigel, which tends to mimic the ECM, and the tube formation can be analyzed with imaging techniques. Data can only be collected in cases where ECs are plated entirely without the presence of fibroblasts or cancerous cells, and the existence of lumens within the capillary-like structures should also be verified. ${ }^{73}$ Although this is typically a two-dimensional method, it can also be performed to assess angiogenesis in three-dimensions. ECs are grown and plated between layers of Matrigel, and generally, tubes are formed horizontally between layers. This presents a more accurate representation of the physiological environment but it also makes it more difficult and time-consuming to analyze tube formation. ${ }^{73,78}$ Coculture assays can also be used to assess tubulogenesis. A coculture model is composed by a twochamber well, separated by a porous polycarbonate membrane. What is cultured in each chamber can be manipulated and, depending on the presence of a stimulant or an inhibitor, ECs will sprout and form capillaries or reduce their activity, respectively. ECs are then stained with a specific antibody, CD31/PECAM, and imaged microscopically.

3.2. Ex Vivo Assays. 3.2.1. Thoracic Aorta Ring (TAR). This is one of the most used methods to study the angiogenic process. The aorta is dissected, placed in either collagen or fibrin gels, and cultured in serum-free media, allowing vessel sprouting. The sprouts can be measured by staining and microscopic observation. The TAR method has several advantages such as being physiologically relevant with new vessel formation with the support of the surrounding cells. It is a relatively fast and inexpensive assay, scalable, with minimum inflammatory response. Clear and visible tubes are formed and developed in a time scale similar to that in vivo. It is not timeconsuming and allows the assembly of different types of data. However, it requires fresh tissue, it does not completely mimic the physiological conditions because other tissues are not involved, and there is no blood flow. Additionally, vessel regression occurs, limiting the analysis over time. ${ }^{73,79}$

3.2.2. Ex Vivo Retina Angiogenesis. In this method, new vessels form from mature and quiescent pre-existing retinal vessels. A three-dimensional fibrin gel is used to culture fragments of retina obtained from adult mice. In the presence of human recombinant VEGF, endothelial cells start sprouting into the fibrin gel and can be observed over time using an inverted microscope. The ability to evaluate potential proangiogenic factors and the precise analysis of new sprouts from pre-existing adult retina vessels are some of the advantages of this method. On the other hand, there are no circulating endothelial progenitors, hormonal factors, and blood flow, which all have a great influence on the angiogenic process. 73,80

3.3. In Vivo Assays. In vivo assays generally obtain more reliable information on the influence of the biomolecule or material in question, within an organism. A final confirmation of results using these assays should always be complemented with information obtained from in vitro studies.

3.3.1. Chick Chorioallantoic Membrane (CAM). This is an old and frequently used assay that is based on the existence of the chorioallantoic membrane in fertilized eggs, which hosts a considerable vessel network. After a few days of incubation, a small piece of shell is cut off to access the CAM. The "window" is closed to protect the membrane and the eggs are incubated for a few more days. The "window" is opened, the agent is placed on top of the CAM, the "window" is closed, and the eggs are incubated once more. After this final incubation step, the region of the membrane that hosts the agent is removed from the egg and imaged. An alternative CAM method can also be performed, where the embryo is removed from the shell and cultured in a Petri dish before the agent is introduced. The CAM assay is frequently used due to its easy technical reproducibility, ability to do large-scale screening, inexpensiveness, and ease of observation of new vascularization. Additionally, ethically speaking, this method is the most acceptable to study angiogenesis in vivo. However, it is not the easiest method to use for weak pro-angiogenic agents due to the numerous blood vessels present in the CAM. ${ }^{3,81}$ 


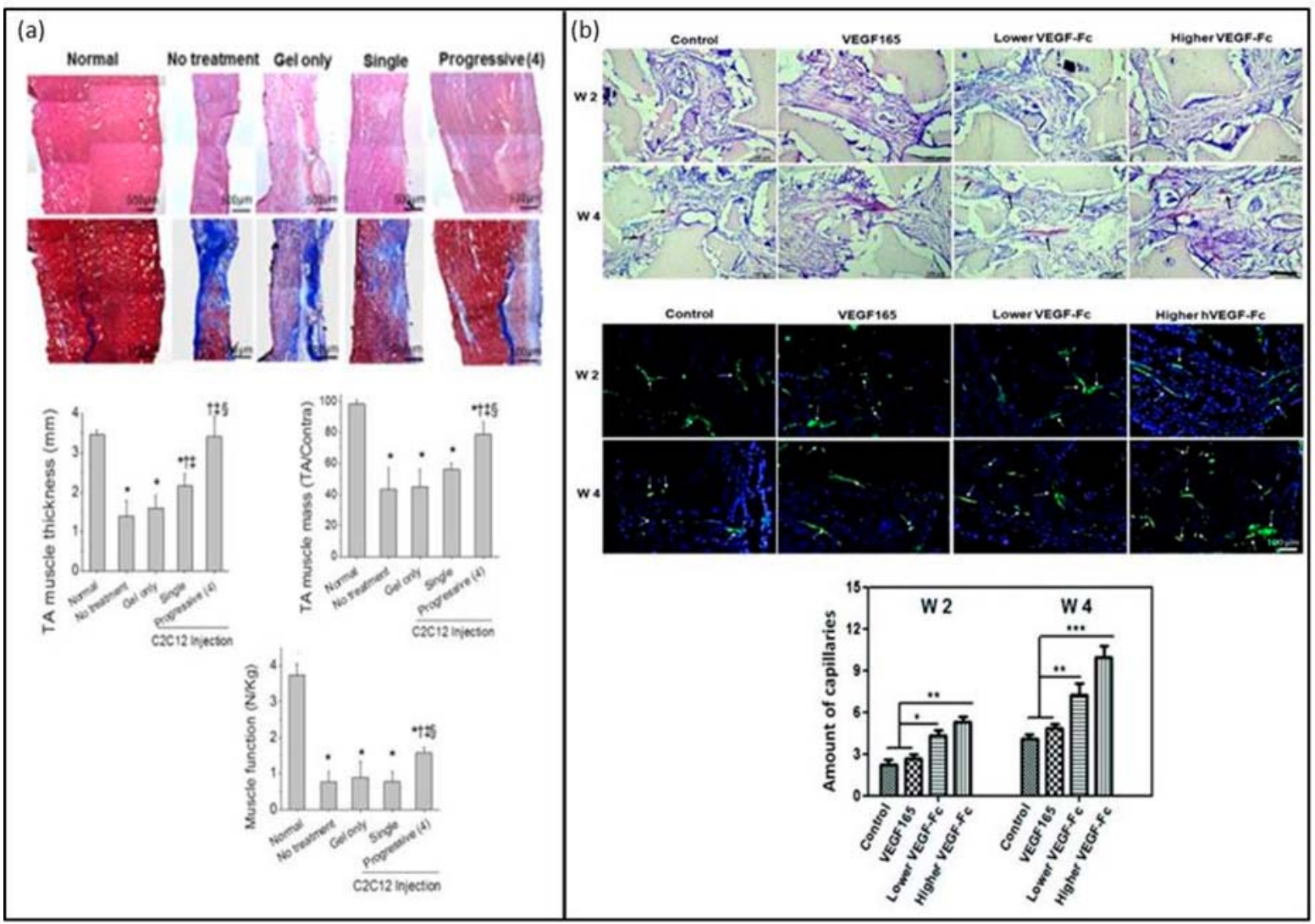

Figure 4. Stimulation/control of angiogenesis in TE constructs. (a) Evaluation of volumetric skeletal muscle tissue reconstruction after creation of Tibialis anterior (TA) muscle injury and multiple cell injections in a progressive manner. Quantitative analysis of TA muscle thickness, mass, and function $\left(\mathrm{N} \mathrm{kg}^{-1}\right)$ after both $\mathrm{C} 2 \mathrm{C} 12$ and hMPC injection. (b) HE and immunofluorescence staining of capillaries onto PCL scaffolds, scale bar = $100 \mu \mathrm{m}$, using different concentrations of VEG-Fc. Quantity of capillaries in each scaffold was quantified. The data indicate means \pm SD of $n=3$ experiments. $* * * P<0.001 ; * * P<0.01 ; * P<0.05$. (a) Reproduced from ref 94 . Copyright 2016, The Authors. (b) Reproduced from ref 86 with permission from The Royal Society of Chemistry, 2018.

3.3.2. Zebrafish Assay. The zebrafish assay is, in many ways, a very advantageous method to use. It involves the injection of a test agent into the yolk sac. In case of lipophilic agents, these can freely enter the embryos by diffusion. The effects on vascularization can be observed due to the transparency of the zebrafish embryos that develop outside the mother. Additionally, the vasculature can be highlighted via fluorescent dyes, quantum dots, or microspheres and analyzed by confocal microscopy and image reconstruction. Thus, the rapid development, transparency, and easy genetic manipulation of the zebrafish embryos, together with the numerous offspring per birth, makes this assay very appealing. Moreover, the cardiovascular system appears very early in the zebrafish development, facilitating the observation of the angiogenic process, and studies have shown that the molecular pathways between fish and mammals are conserved, which allows direct translation of the findings in this zebrafish model into potential information for human health. However, the type of vascularization that occurs must be distinguished between angiogenesis and vasculogenesis. $5,73,82$

3.3.3. Corneal Angiogenesis Assay. The corneal angiogenesis assay takes advantage of the natural lack of blood vessels in the cornea to visualize and assess new vascular formation. This method is performed by creating a stromal "pocket" immediately behind the cornea, where the angiogenic agent will be placed. Usually, the delivery of these agents is done progressively, with the help of slow-release pellets or sponges. These new vessels can then be stained and the images can be analyzed. This method is quantitative, easy to reproduce and to visualize, and does not need a background measurement due to the lack of vessels in the tissue. Thus, vessels observed in the cornea only result form the angiogenic process. However, it comes with associated ethical issues since it manipulates an important organ of a living animal. It is a costly process, and the methods used to form stromal pockets need to be improved. ${ }^{73,83}$

3.3.4. Matrigel Plug Assay. The Matrigel plug is another common assay to study angiogenesis. Matrigel is used not only due to its similarity to the ECM but also because it exists as a liquid state at cold temperatures $\left(4{ }^{\circ} \mathrm{C}\right)$ and gelfies when subjected to warmer temperatures $\left(37^{\circ} \mathrm{C}\right)$. Thus, in this method, subcutaneous injection of Matrigel or implantation of a polymer scaffold is performed, usually in rat or mouse, and once solidified, angiogenic agents are inserted via slow-release pellets or sponges. Following an incubation step, the Matrigel plug is removed, stained, and imaged. The vessels present in the plug can be measured using endothelial markers or by analyzing the hemoglobin content. Some disadvantages of this method are the fact that Matrigel is expensive and the possibility of systemic error in the data due to the use of different sponges containing slow-release pellets ${ }^{5,73}$

3.3.5. Chamber Assays. The creation of a transparent chamber has also been used to assess angiogenesis. In the rabbit ear chamber assay, a piece of skin is removed and the 
angiogenic agent is introduced on the exposed area, which is then covered by glass. After the animal recovery, gene expression, angiogenesis, $\mathrm{pH}$ and blood flow can be measured in a living organism. This model has been used to study structural and functional changes in the formation of new vessels in tumors. ${ }^{84}$ In the dorsal skinfold chamber, the protocol is similar but it has been used to introduce xenografts in immunodeficient rodents and to understand the role of the angiogenic process in tumor growth and wound healing. For the cranial window chamber, a part of the skull is removed to create the transparent chamber. This method has been used to understand pial microcirculation. The results obtained using these assays can be quantified using microscopy. 3D vessel growth throughout 1-3 weeks using only one animal is a major advantage of these assays since it allows reducing the number of animals used. However, these are invasive, technically demanding, and time-consuming assays. Additionally, due to the thickness of the skin, it is difficult to observe the vessels in the skinfold chamber and, in the cranial window assay, the use of fluorescent markers is needed for imaging of new vessels. ${ }^{77,85}$

3.3.6. Dorsal Air Sac Assay. The dorsal skin air sac model has been used to understand angiogenesis triggered by tumors. For this technique, a chamber is created with Millipore rings and filters, and then a tumor cell suspension is injected into this chamber. An air pocket is created on the dorsum of a rat, which forms a temporarily isolated vascularized membrane, and the chamber is placed inside. The chamber is then removed and newly formed vessels can be counted using a dissecting microscope. This method is relatively easy to use but attention is required for the creation of the chamber, avoiding irritation of the surface since this itself can lead to neovascularization and mask the vascularization initiated by the presence of the tumor. ${ }^{77}$

\section{STIMULATING/CONTROLLING ANGIOGENESIS IN TE CONSTRUCTS}

4.1. Angiogenic Growth Factor (AGF) Delivery. With respect to physiological considerations, there is a set of factors that play a crucial role during the formation of new vessels. Vascular endothelial growth factor (VEGF) is responsible for the differentiation of angioblasts with new sprouts induced by angiopoietins. The stabilization of these new vessels is regulated by platelet-derived growth factor (PDGF) and transforming growth factor- $\beta 1$ (TGF- $\beta 1$ ). It involves recruiting vascular smooth muscle cells (SMCs) and pericytes, as well as ECM formation. At this step of neovascularization, other factors such as blood flow, shear stress, and presence of oxygen are of utmost importance, ultimately releasing VEGF from its role and assuring the independence of the endothelial cells. Finally, matrix metalloproteinases release pro-angiogenic factors present in the matrix, regulate further branching, and remodel new vessels. ${ }^{86}$ Thus, the incorporation of these proangiogenic factors into the constructs have also been explored as a way to stimulate and control angiogenesis in constructs (Figure 4). Xu et al. ${ }^{86}$ developed a polycarprolactone (PCL) porous scaffold with a bioactive interface composed of human VEGF fused with an immunoglobulin G Fc region (VEGF-Fc). This formulation not only improved adhesion and proliferation of human vascular endothelial cells (HUVECs), but it also promoted the migration of these cells into the scaffolds, leading to neovascularization in vivo. Correa do Amaral et al. ${ }^{87}$ added PDGF-BB to a collagen-glycosaminoglycan (CG) scaffold to avoid regression of the newly formed vessels. After 10 days of culture, the added growth factor stabilized the new vasculature, which was further confirmed by analysis of the expression of certain angiogenic genes. To better mimic the spatiotemporal delivery of growth factors, the use of several growth factors with controlled release has been studied. Awada et al. $^{88}$ embedded VEGF in fibrin gel with a distribution of PDGF in a heparin-based coacervate. In a rat model, the sequential delivery of these growth factors promoted the formation and stabilization of newly formed vessels, thus promoting cardiomyocyte survival. Chiu and Radisic ${ }^{89}$ developed 3D-porous collagen scaffolds with VEGF and Angiopoietin-1 (Ang1). Culturing over a few days led to increased proliferation of endothelial cells into the scaffolds.

4.2. Cell-Based Strategies. Another approach to control/ stimulate vascularization is based on the use of cells (Figure 4). The coculture of cells promotes the development of a vascular network. Coculture with fibroblasts, keratinocytes, pericytes and vascular smooth muscle cells, which are responsible for providing structure to vascular walls in vivo, can enhance differentiation of cultured endothelial cells, promoting vessel formation. ${ }^{2}$ Kim et al. ${ }^{90}$ developed a triculture system composed of human pericytes, fibroblasts, and endothelial cells, to promote vascularization of a nanografted substrate composed of polydimethylsiloxane in vitro. Capillary-like tubular structures formed with subsequent ECM formation, displaying that the triculture system promotes angiogenesis. Mesenchymal stem cells (MSCs) have also been used in coculture with endothelial cells. Freiman et al. ${ }^{94}$ cocultured adipose-derived MSCs with human adipose-derived microvascular endothelial cells (HAMECs) to promote vascularization in a three-dimensional scaffold, in vitro. A well organized and complex vasculature was formed in a short period of time. Another approach of cell-based strategies for vascularization is cell sheet technology. It uses a temperature responsive surface that allows the harvesting of an intact cell sheet. This is achieved by treating them with poly $(N$-isopropylacrylamide $)$ (PIPAAm), which oscillates between hydrophilic and hydrophobic states according to the temperature. Temperatures higher than $32{ }^{\circ} \mathrm{C}$ lead to a hydrophilic state, which means that at a regular culture temperature $\left(37^{\circ} \mathrm{C}\right)$, PIPAAm offers a normal cell culture environment. However, at temperatures lower than $32{ }^{\circ} \mathrm{C}$, the surface state is changed to hydrophobic and the rapid hydration and swelling of PIPAAm leads to a spontaneous detachment of the cell sheet. ${ }^{91}$ Some clear advantages of this technology are the easy manipulation of the cells and the maintenance of cell-to-cell interactions and ECM development, which is usually damaged by treatment with trypsin. Alternatively, to the thermoresponsive approach, there are also electro-, photo-, $\mathrm{pH}-$, and magnetic-responsive systems. The cell sheet, when formed by fusion with a rolled-up edge, can also be harvested by the mechanical peeling method. The thermoresponsive approach is sensitive to the thickness and density of the grafted polymer chains. Both electro- and magnetic-responsive approaches may add residual materials to the cell sheets. In the mechanical peeling method, the manipulation of the cells ${ }^{91}$ can be challenging. ${ }^{92}$ Ren et al. ${ }^{15}$ developed a synthetic biomimetic induced membrane (BIM) with an inner highly prevascularized cell sheet and an outer osteogenic layer for the treatment of bone defects. Results showed a significant development of vascular-like networks and, after implantation of the construct, rapid vascularization and anastomosis to the host vessels occurred. 
Sakaguchi et al. ${ }^{92}$ constructed $3 \mathrm{D}$ tissues by layering cell sheets. For that, there is a need of medium and blood perfusion within the different cells' sheets, thus two types of vascular beds were developed. Functional vascularized 3D tissues were developed. Additionally, the progressive layering technique can also be used, which takes advantage of the natural host regeneration process for vascularization. ${ }^{2}$ Kim et al. ${ }^{93}$ performed multiple injections of cells, in a progressive manner, in a rodent volumetric muscle loss (VML) model. The muscle tissue was successfully reconstructed, including integration of host vasculature and neurons, with function recovered.

4.3. Intelligent Scaffold Design. Intelligent scaffolds arouse from the realization that the ECM not only provides support for the cells but also regulates functions such as proliferation, migration, differentiation, among others. ${ }^{95}$ Thus, these "smart" scaffolds tend to mimic this dynamic nature of the ECM by being biodegradable, enabling their reabsorption without secondary effects, and bioactive, eliciting a specific cell response. $^{96}$ Aguirre et al. ${ }^{96}$ developed a smart polylactic acid (PLA)/calcium phosphate glass composite biomaterial to mimic the high extracellular calcium concentration present in bone healing microenvironment as well as the matrix stiffness provided by the osteoid. Angiogenesis was improved due to the activation of angiogenic pathways by the scaffold. Cui et al. ${ }^{97}$ integrated a biomimetic $3 \mathrm{D}$ bioprinted fluid perfused microstructure with a smart release nanocoating. There was a successive induction of angiogenesis and osteogenesis via a spatiotemporally coordinated delivery of dual growth factors. Hokugo et al. ${ }^{98}$ focused on chemotaxis. They developed an apatite-coated polylactic-co-glycolic acid scaffold where engineered human mesenchymal stem cells overexpressing VEGF were seeded. The continuous release of VEGF attracts mesenchymal stem cells to the site of injury, inducing angiogenesis and subsequently promoting tissue regeneration.

4.4. Immobilization of Molecules. There are several ways to immobilize molecules either on the surface or inside constructs. Surface immobilization of biomolecules can be achieved by chemical incorporation, which can be via noncovalent or covalent methods. Noncovalent incorporation (physical adsorption) takes advantage of surface interactions such as van der Waal forces, electrostatic forces, hydrophobic interactions and hydrogen bonds. Noncovalent incorporation presents advantages like simplicity and, in the case of fragile structures or biomolecules, it is quite benign. ${ }^{99}$ For example, Park et al. ${ }^{100}$ loaded gelatin microparticles (MPs) with transforming growth factor- $\beta 1$ (TGF- $\beta 1$ ) via noncovalent incorporation. The MPs were immersed in an aqueous TGF$\beta 1$ solution at $\mathrm{pH} 7.4$ for $15 \mathrm{~h}$. While covalent incorporation is based on chemically bonding biomolecules to a relevant functional group in the scaffold. This is a more efficient bond as the biomolecules are retained for a longer period of time. Chiu and Radisic, ${ }^{89}$ developed $3 \mathrm{D}$ porous collagen scaffold and covalently immobilized VEGF and Ang1 onto it. Increased proliferation of endothelial cells and infiltration in the CAM assay was observed. Miyagi et al. ${ }^{101}$ developed an ultrafoam collagen sponge scaffold with VEGF covalently immobilized onto it, with the aim to replace a full right ventricular free wall defect in rat hearts. In vivo, neovascularization was observed with improved cell survival and tissue formation. Another surface immobilization technique takes advantage of linker molecules, and it is usually used when the biomolecules cannot be directly grafted onto the polymer surface. These linker molecules will bind to the biomolecule and then to the biomaterial surface. ${ }^{99}$ Guo et al. ${ }^{102}$ used a glycosaminoglycan as a linker molecule. The authors developed a self-assembling peptide, heparin-binding domain sequence attached to a selfassembling peptide, which in turn attaches to the nanofiber scaffold under physiological conditions. This allowed a sustained release of VEGF, improving cardiac function and microvessel density. Layman et al. ${ }^{103}$ opted to use components from the ECM as a linker molecule. The authors coimmobilized FGF-2 and human recombinant granulocyte colony-stimulating factor (G-CSF) into gelatin-based hydrogel scaffolds, promoting mature vessel formation in a murine hindlimb ischemic model. Davis et al. ${ }^{104}$ explored the avidinbiotin binding system. The aim was to design a self-assembling peptide nanofiber for sustained delivery of insulin-like growth factor 1 (IGF-1) into the myocardium. IGF-1 was biotinylated, complexed with tetravalent streptavidin and bound again to a biotinylated self-assembling peptides, which was in turn attached to the nanofibers.

Regarding incorporation of biomolecules into the core of constructs, techniques such as direct mixing, coaxial incorporation (electrospinning), and self-assembling (amphiphile) peptide nanofibers can be used. In this case, it can be a continuous release of biomolecules by diffusion or degradation of the polymer. ${ }^{99}$ In the direct mixing technique, the biomolecules and the polymer solution can be directly mixed as the name suggests. For example, Ruvinov et al. ${ }^{105}$ incorporated a biconjugate composed of hepatocyte growth factor (HGF) with alginate-sulfate into an alginate hydrogel. This injectable biomaterial enabled sustained release of HGF in a severe murine hindlimb ischemia model, promoting neovascularization as well as blood perfusion. Kraehenbuehl et al. ${ }^{106}$ developed a synthetic, injectable matrix metalloproteinase (MMP)-responsive, bioactive hydrogel for thymosin $\beta 4$ (T $\beta 4$ ) and vascular cells derived from human embryonic stem cells (hESC). In an ischemic injury in a rat model, the scaffold promoted the formation of new blood vessels. Another bulk incorporation technique involves the self-assembling peptide nanofibers where biofunctional peptide sequences are incorporated into amphiphile peptides, which in turn self-assemble into nanofibers. ${ }^{99}$ Lin et al. ${ }^{107}$ developed RAD16-II peptide nanofibers for intramyocardial injection to promote cardiac remodeling in a pig model. The injection of the peptide nanofibers along with bone marrow cells (MNCs) increased angiogenesis after infarction. Kim et al. ${ }^{108}$ used the selfassembling peptides for dual delivery of growth factors PDGF$\mathrm{BB}$ and FGF-2. The formation of new vessels was observed leading to improved cardiac function.

\section{CONCLUSION}

Looking to the future, a highly organized vascular network that is able to supply all cells with sufficient nutrients needs to be achieved in an optimal tissue engineered structure, comprising venules, capillaries, and arterioles. Introducing spatially controlled micro patterns into the developed constructs, using bioprinting techniques, for example, can promote the direct perfusion of blood after implantation. However, some authors argue that patterning vascular cells in engineered tissues may not be sufficient to ensure a good vascular organization in the long term as the vasculature is likely to revert to a disorganized state upon implantation without additional cues. However, the authors do agree that patterning of endothelial cells will provide a valid starting point. Because of the myriad of varying tissue types, it is unlikely that one 
single optimal method to add a vascular network to engineered tissues will be realized rather a mix of various cell types form differing sources will be utilized. Therefore, it is of critical importance that in vitro and in vivo methods utilized to assess vascularization degree and structure continue to be developed.

\section{AUTHOR INFORMATION}

\section{Corresponding Author}

Joana Silva-Correia - 3B's Research Group, Research Institute on Biomaterials, Biodegradables and Biomimetics, Headquarters of the European Institute of Excellence on Tissue Engineering and Regenerative Medicine, University of Minho, Guimarães 4805-017, Portugal; ICVS/3B's - PT Government Associate Laboratory, Braga/Guimarães,

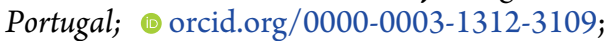
Phone: +351 253510933; Email: joana.correia@ i3bs.uminho.pt; Fax: +351 253510909

\section{Authors}

Soraia V. Lopes - 3B's Research Group, Research Institute on Biomaterials, Biodegradables and Biomimetics, Headquarters of the European Institute of Excellence on Tissue Engineering and Regenerative Medicine, University of Minho, Guimarães 4805-017, Portugal; ICVS/3B's - PT Government Associate Laboratory, Braga/Guimarães, Portugal; 이잉.org/00000002-3705-2619

Maurice N. Collins - Bernal Institute, School of Engineering, University of Limerick, Limerick V94 T9PX, Ireland; (1) orcid.org/0000-0003-2536-4508

Rui L. Reis - 3B's Research Group, Research Institute on Biomaterials, Biodegradables and Biomimetics, Headquarters of the European Institute of Excellence on Tissue Engineering and Regenerative Medicine, University of Minho, Guimarães 4805-017, Portugal; ICVS/3B's - PT Government Associate Laboratory, Braga/Guimarães, Portugal

Joaquim M. Oliveira - 3B's Research Group, Research Institute on Biomaterials, Biodegradables and Biomimetics, Headquarters of the European Institute of Excellence on Tissue Engineering and Regenerative Medicine, University of Minho, Guimarães 4805-017, Portugal; ICVS/3B's - PT Government Associate Laboratory, Braga/Guimarães, Portugal

Complete contact information is available at: https://pubs.acs.org/10.1021/acsabm.1c00051

\section{Notes}

The authors declare no competing financial interest.

\section{ACKNOWLEDGMENTS}

The authors acknowledge the financial support provided through the projects B-FABULUS (PTDC/BBB-ECT/2690/ 2014) and Fun4TE (PTDC/EMD-EMD/31367/2017), financed by the Portuguese Foundation for Science and Technology (FCT) and cofinanced by European Regional Development Fund (FEDER) and Operational Programme for Competitiveness and Internationalisation (POCI). This work was also partly supported by H2020-MSCA-RISE BAMOS project, funded from the European Union's Horizon 2020 research and innovation program under Grant Agreement No. 734156. S.V.L. acknowledges FCT for the PhD grant (SFRH/ $\mathrm{BD} / 143954 / 2019)$. The FCT distinction attributed to J.S.-C. (IF/00115/2015) under the Investigator FCT program is also greatly acknowledged.

\section{REFERENCES}

(1) Lim, K. S.; Baptista, M.; Moon, S.; Woodfield, T. B. F.; RnjakKovacina, J. Microchannels in Development, Survival, and Vascularisation of Tissue Analogues for Regenerative Medicine. Trends Biotechnol. 2019, 37 (11), 1189-1201.

(2) Min, S.; Ko, I. K.; Yoo, J. J. State-of-the-Art Strategies for the Vascularization of Three-Dimensional Engineered Organs. Vascular Specialist International 2019, 35 (2), 77-89.

(3) Adair, T., Montani, J. Angiogenesis; Morgan \& Claypool Life Sciences, San Rafael, CA, 2010.

(4) Carmeliet, P.; Jain, R. K. Molecular mechanisms and clinical applications of angiogenesis. Nature 2011, 473 (7347), 298-307.

(5) Irvin, M. W.; Zijlstra, A.; Wikswo, J. P.; Pozzi, A. Techniques and assays for the study of angiogenesis. Exp. Biol. Med. (London, U. K.) 2014, 239 (11), 1476-1488.

(6) Banfi, A.; Holnthoner, W.; Martino, M. M.; Ylä-Herttuala, S. Editorial: Vascularization for Regenerative Medicine. Front. Bioeng. Biotechnol. 2018, 6, 175-175.

(7) Guerra, A.; Belinha, J.; Jorge, R. N. Modelling skin wound healing angiogenesis: A review. J. Theor. Biol. 2018, 459, 1-17.

(8) Karimi, F.; O'Connor, A. J.; Qiao, G. G.; Heath, D. E. Integrin Clustering Matters: A Review of Biomaterials Functionalized with Multivalent Integrin-Binding Ligands to Improve Cell Adhesion, Migration, Differentiation, Angiogenesis, and Biomedical Device Integration. Adv. Healthcare Mater. 2018, 7 (12), 1701324.

(9) Chellappan, D. K.; Leng, K. H.; Jia, L. J.; Aziz, N. A. B. A.; Hoong, W. C.; Qian, Y. C.; Ling, F. Y.; Wei, G. S.; Ying, T.; Chellian, J.; Gupta, G.; Dua, K. The role of bevacizumab on tumour angiogenesis and in the management of gynaecological cancers: A review. Biomed. Pharmacother. 2018, 102, 1127-1144.

(10) Reichard, A.; Asosingh, K. The role of mitochondria in angiogenesis. Mol. Biol. Rep. 2019, 46 (1), 1393-1400.

(11) Devesa, J.; Caicedo, D. The Role of Growth Hormone on Ovarian Functioning and Ovarian Angiogenesis. Front. Endocrinol. 2019, 10, 450.

(12) Marchand, M.; Monnot, C.; Muler, L.; Germain, S. Extracellular matrix scaffolding in angiogenesis and capillary homeostasis. Semin. Cell Dev. Biol. 2019, 89, 147-156.

(13) Novosel, E. C.; Kleinhans, C.; Kluger, P. J. Vascularization is the key challenge in tissue engineering. Adv. Drug Delivery Rev. 2011, 63 (4), 300-311.

(14) Chen, G.; Dong, C.; Yang, L.; Lv, Y. 3D Scaffolds with Different Stiffness but the Same Microstructure for Bone Tissue Engineering. ACS Appl. Mater. Interfaces 2015, 7 (29), 15790-15802.

(15) Ren, L.; Kang, Y.; Browne, C.; Bishop, J.; Yang, Y. Fabrication, vascularization and osteogenic properties of a novel synthetic biomimetic induced membrane for the treatment of large bone defects. Bone 2014, 64, 173-182.

(16) Laschke, M. W.; Menger, M. D. Prevascularization in tissue engineering: Current concepts and future directions. Biotechnol. Adv. 2016, 34 (2), 112-121.

(17) Saberianpour, S.; Heidarzadeh, M.; Geranmayeh, M. H.; Hosseinkhani, H.; Rahbarghazi, R.; Nouri, M. Tissue engineering strategies for the induction of angiogenesis using biomaterials. J. Biol. Eng. 2018, 12 (1), 36.

(18) Sarker, M. D.; Naghieh, S.; Sharma, N. K.; Ning, L.; Chen, X. Bioprinting of Vascularized Tissue Scaffolds: Influence of Biopolymer, Cells, Growth Factors, and Gene Delivery. Journal of Healthcare Engineering 2019, 2019, 9156921.

(19) Crosby, C. O.; Zoldan, J. Mimicking the physical cues of the ECM in angiogenic biomaterials. Regenerative Biomaterials 2019, 6 (2), 61-73.

(20) Lee, J.-H.; Parthiban, P.; Jin, G.-Z.; Knowles, J. C.; Kim, H.-W. Materials roles for promoting angiogenesis in tissue regeneration. Prog. Mater. Sci. 2021, 117, 100732.

(21) Castellanos, M. I.; Guillem-Marti, J.; Mas-Moruno, C.; DíazRicart, M.; Escolar, G.; Ginebra, M. P.; Gil, F. J.; Pegueroles, M.; Manero, J. M. Cell adhesive peptides functionalized on $\mathrm{CoCr}$ alloy 
stimulate endothelialization and prevent thrombogenesis and restenosis. J. Biomed. Mater. Res., Part A 2017, 105 (4), 973-983.

(22) Lee, M. H.; Ducheyne, P.; Lynch, L.; Boettiger, D.; Composto, R. J. Effect of biomaterial surface properties on fibronectin $-\alpha 5 \beta 1$ integrin interaction and cellular attachment. Biomaterials 2006, 27 (9), 1907-1916.

(23) Slater, J. H.; Frey, W. Nanopatterning of fibronectin and the influence of integrin clustering on endothelial cell spreading and proliferation. J. Biomed. Mater. Res., Part A 2008, 87 (1), 176-195.

(24) Bettinger, C. J.; Zhang, Z.; Gerecht, S.; Borenstein, J. T.; Langer, R. Enhancement of In Vitro Capillary Tube Formation by Substrate Nanotopography. Adv. Mater. 2008, 20 (1), 99-103.

(25) Kim, T. H.; Kim, S. H.; Jung, Y. The effects of nanotopography and coculture systems to promote angiogenesis for wound repair. Nanomedicine 2016, 11 (22), 2997-3007.

(26) Byfield, F. J.; Reen, R. K.; Shentu, T.-P.; Levitan, I.; Gooch, K. $\mathrm{J}$. Endothelial actin and cell stiffness is modulated by substrate stiffness in 2D and 3D. J. Biomech. 2009, 42 (8), 1114-1119.

(27) Santos, L.; Fuhrmann, G.; Juenet, M.; Amdursky, N.; Horejs, C.-M.; Campagnolo, P.; Stevens, M. M. Extracellular Stiffness Modulates the Expression of Functional Proteins and Growth Factors in Endothelial Cells. Adv. Healthcare Mater. 2015, 4 (14), 2056-2063.

(28) Ehrbar, M.; Djonov, V. G.; Schnell, C.; Tschanz, S. A.; MartinyBaron, G.; Schenk, U.; Wood, J.; Burri, P. H.; Hubbell, J. A.; Zisch, A. H. Cell-Demanded Liberation of VEGF121 From Fibrin Implants Induces Local and Controlled Blood Vessel Growth. Circ. Res. 2004, 94, 1124-1132.

(29) Klenke, F. M.; Liu, Y.; Yuan, H.; Hunziker, E. B.; Siebenrock, K. A.; Hofstetter, W. Impact of pore size on the vascularization and osseointegration of ceramic bone substitutes in vivo. J. Biomed. Mater. Res., Part A 2008, 85 (3), 777-786.

(30) Chiu, Y. C.; Cheng, M.-H.; Engel, H.; Kao, S.-W.; Larson, J. C.; Gupta, S.; Brey, E. M. The role of pore size on vascularization and tissue remodeling in PEG hydrogels. Biomaterials 2011, 32 (26), 6045-6051.

(31) Walthers, C. M.; Nazemi, A. K.; Patel, S. L.; Wu, B. M.; Dunn, J. C. Y. The effect of scaffold macroporosity on angiogenesis and cell survival in tissue-engineered smooth muscle. Biomaterials 2014, 35 (19), 5129-5137.

(32) Xiao, X.; Wang, W.; Liu, D.; Zhang, H.; Gao, P.; Geng, L.; Yuan, Y.; Lu, J.; Wang, Z. The promotion of angiogenesis induced by three-dimensional porous beta-tricalcium phosphate scaffold with different interconnection sizes via activation of PI3K/Akt pathways. Sci. Rep. 2015, 23 (5), 9409.

(33) Somo, S. I.; Akar, B.; Bayrak, E. S.; Larson, J. C.; Appel, A. A.; Mehdizadeh, H.; Cinar, A.; Brey, E. M. Pore Interconnectivity Influences Growth Factor-Mediated Vascularization in SphereTemplated Hydrogels. Tissue Eng., Part C 2015, 21 (8), 773-785.

(34) Li, Y.; Fan, P.; Ding, X.-M.; Tian, X.-H.; Feng, X.-S.; Yan, H.; Pan, X.-M.; Tian, P.-X.; Zheng, J.; Ding, C.-G.; Xue, W.-J. Polyglycolic Acid Fibrous Scaffold Improving Endothelial Cell Coating and Vascularization of Islet. Chinese Medical Journal 2017, 130, 832.

(35) Caldara, G.; Rigogliuso, S.; Pavia, F. C.; Brucato, V. Biocompatibility evaluation of PLLA scaffolds for vascular tissue engineering. Italian Journal of Anatomy and Embryology 2015, 119 (1), 31.

(36) Laschke, M. W.; Strohe, A.; Scheuer, C.; Eglin, D.; Verrier, S.; Alini, M.; Pohlemann, T.; Menger, M. D. In vivo biocompatibility and vascularization of biodegradable porous polyurethane scaffolds for tissue engineering. Acta Biomater. 2009, 5 (6), 1991-2001.

(37) Dong, C.; Lv, Y. Application of Collagen Scaffold in Tissue Engineering: Recent Advances and New Perspectives. Polymers 2016, 8,42 .

(38) Chan, E. C.; Kuo, S.-M.; Kong, A. M.; Morrison, W. A.; Dusting, G. J.; Mitchell, G. M.; Lim, S. Y.; Liu, G.-S. Three Dimensional Collagen Scaffold Promotes Intrinsic Vascularisation for Tissue Engineering Applications. PLoS One 2016, 11 (2), e0149799e0149799.
(39) Noori, A.; Ashrafi, S. J.; Vaez-Ghaemi, R.; Hatamian-Zaremi, A.; Webster, T. J. A review of fibrin and fibrin composites for bone tissue engineering. Int. J. Nanomed. 2017, 12, 4937-4961.

(40) Morin, K. T.; Tranquillo, R. T. In vitro models of angiogenesis and vasculogenesis in fibrin gel. Exp. Cell Res. 2013, 319 (16), 24092417.

(41) Urech, L.; Bittermann, A. G.; Hubbell, J. A.; Hall, H. Mechanical properties, proteolytic degradability and biological modifications affect angiogenic process extension into native and modified fibrin matrices in vitro. Biomaterials 2005, 26 (12), 13691379.

(42) Jiang, B.; Waller, T. M.; Larson, J. C.; Appel, A. A.; Brey, E. M. Fibrin-loaded porous poly(ethylene glycol) hydrogels as scaffold materials for vascularized tissue formation. Tissue Eng., Part A 2013, 19 (1-2), 224-234.

(43) Schmidt, V.; Wietbrock, J. O.; Leibig, N.; Gloe, T.; Henn, D.; Hernekamp, J. F.; Harhaus, L.; Kneser, U. Collagen-Elastin and Collagen-Glycosaminoglycan Scaffolds Promote Distinct Patterns of Matrix Maturation and Axial Vascularization in Arteriovenous LoopBased Soft Tissue Flaps. Ann. Plast. Surg. 2017, 79 (1), 92-100.

(44) Unger, R. E.; Ghanaati, S.; Orth, C.; Sartoris, A.; Barbeck, M.; Halstenberg, S.; Motta, A.; Migliaresi, C.; Kirkpatrick, C. J. The rapid anastomosis between prevascularized networks on silk fibroin scaffolds generated in vitro with cocultures of human microvascular endothelial and osteoblast cells and the host vasculature. Biomaterials 2010, 31 (27), 6959-6967.

(45) Li, S.; Yu, D.; Ji, H.; Zhao, B.; Ji, L.; Leng, X. In vivo degradation and neovascularization of silk fibroin implants monitored by multiple modes ultrasound for surgical applications. BioMedical Engineering OnLine 2018, 17 (1), 87.

(46) Sun, J.; Tan, H. Alginate-Based Biomaterials for Regenerative Medicine Applications. Materials 2013, 6 (4), 1285-1309.

(47) Nemati, S.; Rezabakhsh, A.; Khoshfetrat, A. B.; Nourazarian, A.; Avci, Ç.B.; Bagca, B. G.; Sardroud, H. A.; Khahsar, M.; Ahmadi, M.; Delkhosh, A.; Sokullu, E.; Rahbarghazi, R. Alginate-gelatin encapsulation of human endothelial cells promoted angiogenesis in in vivo and in vitro milieu. Biotechnol. Bioeng. 2017, 114 (12), 2920-2930.

(48) Gerecht-Nir, S.; Cohen, S.; Ziskind, A.; Itskovitz-Eldor, J. Three-dimensional porous alginate scaffolds provide a conducive environment for generation of well-vascularized embryoid bodies from human embryonic stem cells. Biotechnol. Bioeng. 2004, 88 (3), 313-320.

(49) Oryan, A.; Sahvieh, S. Effectiveness of chitosan scaffold in skin, bone and cartilage healing. Int. J. Biol. Macromol. 2017, 104, 10031011.

(50) Hsieh, F.-Y.; Tao, L.; Wei, Y.; Hsu, S.-h. A novel biodegradable self-healing hydrogel to induce blood capillary formation. NPG Asia Mater. 2017, 9 (3), e363-e363.

(51) Malafaya, P. B.; Santos, T. C.; van Griensven, M.; Reis, R. L. Morphology, mechanical characterization and in vivo neo-vascularization of chitosan particle aggregated scaffolds architectures. Biomaterials 2008, 29 (29), 3914-3926.

(52) Silva, L. P.; Pirraco, R. P.; Santos, T. C.; Novoa-Carballal, R.; Cerqueira, M. T.; Reis, R. L.; Correlo, V. M.; Marques, A. P. Neovascularization Induced by the Hyaluronic Acid-Based SpongyLike Hydrogels Degradation Products. ACS Appl. Mater. Interfaces 2016, 8 (49), 33464-33474.

(53) Kenar, H.; Ozdogan, C. Y.; Dumlu, C.; Doger, E.; Kose, G. T.; Hasirci, V. Microfibrous scaffolds from poly(l-lactide-co- $\varepsilon$-caprolactone) blended with xeno-free collagen/hyaluronic acid for improvement of vascularization in tissue engineering applications. Mater. Sci. Eng., C 2019, 97, 31-44.

(54) Song, M.; Zhou, Y.; Liu, Y. VEGF heparinized-decellularized adipose tissue scaffolds enhance tissue engineering vascularization in vitro. RSC Adv. 2018, 8 (59), 33614-33624.

(55) Murali, R.; Ponrasu, T.; Cheirmadurai, K.; Thanikaivelan, P. Biomimetic hybrid porous scaffolds immobilized with platelet derived growth factor-BB promote cellularization and vascularization in tissue engineering. J. Biomed. Mater. Res., Part A 2016, 104 (2), 388-396. 
(56) Gümüşderelioğlu, M.; Karakus, E.; Yurtsever, M.Ç.; Altindal, D.Ç. Inosculation potential of angiopoietin-4-immobilized pHEMAbased bone scaffolds. J. Bioact. Compat. Polym. 2015, 30 (6), 649666.

(57) Zhang, Q.; Qin, M.; Zhou, X.; Nie, W.; Wang, W.; Li, L.; He, C. Porous nanofibrous scaffold incorporated with S1P loaded mesoporous silica nanoparticles and BMP-2 encapsulated PLGA microspheres for enhancing angiogenesis and osteogenesis. J. Mater. Chem. B 2018, 6 (42), 6731-6743.

(58) Li, Y.; Fan, L.; Liu, S.; Liu, W.; Zhang, H.; Zhou, T.; Wu, D.; Yang, P.; Shen, L.; Chen, J.; Jin, Y. The promotion of bone regeneration through positive regulation of angiogenic-osteogenic coupling using microRNA-26a. Biomaterials 2013, 34 (21), 50485058 .

(59) Nelson, C. E.; Kim, A. J.; Adolph, E. J.; Gupta, M. K.; Yu, F.; Hocking, K. M.; Davidson, J. M.; Guelcher, S. A.; Duvall, C. L. Tunable delivery of siRNA from a biodegradable scaffold to promote angiogenesis in vivo. Adv. Mater. (Weinheim, Ger.) 2014, 26 (4), 607506.

(60) Nakasa, T.; Ishikawa, M.; Shi, M.; Shibuya, H.; Adachi, N.; Ochi, M. Acceleration of muscle regeneration by local injection of muscle-specific microRNAs in rat skeletal muscle injury model. Journal of Cellular and Molecular Medicine 2010, 14 (10), 2495-2505. (61) Devalliere, J.; Chang, W. G.; Andrejecsk, J. W.; Abrahimi, P.; Cheng, C. J.; Jane-wit, D.; Saltzman, W. M.; Pober, J. S. Sustained delivery of proangiogenic microRNA-132 by nanoparticle transfection improves endothelial cell transplantation. FASEB J. 2014, 28 (2), 908-922.

(62) Heiss, M.; Hellström, M.; Kalén, M.; May, T.; Weber, H.; Hecker, M.; Augustin, H. G.; Korff, T. Endothelial cell spheroids as a versatile tool to study angiogenesis in vitro. FASEB J. 2015, 29 (7), 3076-3084.

(63) Walser, R.; Metzger, W.; Görg, A.; Pohlemann, T.; Menger, M. D.; Laschke, M. W. Generation of co-culture spheroids as vascularisation units for bone tissue engineering. European Cells \& Materials 2013, 26, 222-33.

(64) Zhou, F.; Zhang, L.; Chen, L.; Xu, Y.; Chen, Y.; Li, Z.; Liu, X.; Wu, J.; Qi, S. Prevascularized mesenchymal stem cell-sheets increase survival of random skin flaps in a nude mouse model. American Journal of Translational Research 2019, 11 (3), 1403-1416.

(65) Dergilev, K.; Tsokolaeva, Z.; Makarevich, P.; Beloglazova, I.; Zubkova, E.; Boldyreva, M.; Ratner, E.; Dyikanov, D.; Menshikov, M.; Ovchinnikov, A.; Ageev, F.; Parfyonova, Y. C-Kit Cardiac Progenitor Cell Based Cell Sheet Improves Vascularization and Attenuates Cardiac Remodeling following Myocardial Infarction in Rats. BioMed. Research International 2018, 2018, 3536854-3536854.

(66) Fu, J.; Wang, D.-A. In Situ Organ-Specific Vascularization in Tissue Engineering. Trends Biotechnol. 2018, 36 (8), 834-849.

(67) Tseng, T.-C.; Hsieh, F.-Y.; Theato, P.; Wei, Y.; Hsu, S.-h. Glucose-sensitive self-healing hydrogel as sacrificial materials to fabricate vascularized constructs. Biomaterials 2017, 133, 20-28.

(68) Mirabella, T.; MacArthur, J. W.; Cheng, D.; Ozaki, C. K.; Woo, Y. J.; Yang, M. T.; Chen, C. S. 3D-printed vascular networks direct therapeutic angiogenesis in ischaemia. Nat. Biomed Eng. 2017, 4 (5), 572.

(69) Baldwin, J.; Antille, M.; Bonda, U.; De-Juan-Pardo, E. M.; Khposrotehrani, K.; Ivanovski, S.; Petcu, E. B.; Hutmacher, D. W. In vitro pre-vascularisation of tissue-engineered constructs A co-culture perspective. Vasc. Cell 2014, 6 (1), 13.

(70) Ciampi, O.; Bonandrini, B.; Derosas, M.; Conti, S.; Rizzo, P.; Benedetti, V.; Figliuzzi, M.; Remuzzi, A.; Benigni, A.; Remuzzi, G.; Tomasoni, S. Engineering the vasculature of decellularized rat kidney scaffolds using human induced pluripotent stem cell-derived endothelial cells. Sci. Rep. 2019, 9 (1), 8001.

(71) Wong, L.; Pegan, J. D.; Gabela-Zuniga, B.; Khine, M.; McCloskey, K. E. Leaf-inspired microcontact printing vascular patterns. Biofabrication 2017, 9 (2), 021001.

(72) Stryker, Z. I.; Rajabi, M.; Davis, P. J.; Mousa, S. A. Evaluation of Angiogenesis Assays. Biomedicines 2019, 7 (2), 37.
(73) Wei, J.; Yang, Y.; Li, Y.; Mo, X.; Guo, X.; Zhang, X.; Xu, X.; Jiang, Z.; You, Q. Synthesis and evaluation of N-(benzofuran-5yl)aromaticsulfonamide derivatives as novel HIF-1 inhibitors that possess anti-angiogenic potential. Bioorg. Med. Chem. 2017, 25 (6), $1737-1746$

(74) Gomez, D.; Reich, N. Stimulation of Primary Human Endothelial Cell Proliferation by IFN. J. Immunol. 2003, 170, 5373-81.

(75) Feng, X.; Tonnesen, M. G.; Mousa, S. A.; Clark, R. A. F. Fibrin and collagen differentially but synergistically regulate sprout angiogenesis of human dermal microvascular endothelial cells in 3dimensional matrix. International Journal of Cell Biology 2013, 2013, 231279-231279.

(76) Staton, C. A.; Stribbling, S. M.; Tazzyman, S.; Hughes, R.; Brown, N. J.; Lewis, C. E. Current methods for assaying angiogenesis in vitro and in vivo. Int. J. Exp. Pathol. 2004, 85 (5), 233-248.

(77) Gagnon, E.; Cattaruzzi, P.; Griffith, M.; Muzakare, L.; LeFlao, K.; Faure, R.; Béliveau, R.; Hussain, S. N.; Koutsilieris, M.; Doillon, C. J. Human vascular endothelial cells with extended life spans: In vitro cell response, protein expression, and angiogenesis. Angiogenesis 2002, 5 (1), 21-33.

(78) Baker, M.; Robinson, S. D.; Lechertier, T.; Barber, P. R.; Tavora, B.; D’Amico, G.; Jones, D. T.; Vojonovic, B.; Hodivala-Dilke, $\mathrm{K}$. Use of the mouse aortic ring assay to study angiogenesis. Nat. Protoc. 2012, 7 (1), 89-104.

(79) Rezzola, S.; Belleri, M.; Ribatti, D.; Costagliola, C.; Presta, M.; Semeraro, F. A novel ex vivo murine retina angiogenesis (EMRA) assay. Exp. Eye Res. 2013, 112, 51-56.

(80) Ribatti, D. The Chick Embryo Chorioallantoic Membrane in the Study of Angiogenesis and Metastasis; Springer: The Netherlands, 2010.

(81) Chávez, M. N.; Aedo, G.; Fierro, F. A.; Allende, M. L.; Egana, J. T. Zebrafish as an Emerging Model Organism to Study Angiogenesis in Development and Regeneration. Frontiers in Physiology 2016, 7, $56-56$.

(82) Birsner, A. E.; Benny, O.; D’Amato, R. J. The corneal micropocket assay: a model of angiogenesis in the mouse eye. $J$. Visualized Exp. 2014, No. 90, 51375.

(83) Sandison, J. A new method for the microscopic study of living growing tissues by the introduction of a transparent chamber in the rabbit's ear. Anat. Rec. 1924, 28 (4), 281-287.

(84) Cimpean, A.-M.; Ribatti, D.; Raica, M. A brief history of angiogenesis assays. Int. J. Dev. Biol. 2011, 55, 377-82.

(85) Lovett, M.; Lee, K.; Edwards, A.; Kaplan, D. L. Vascularization strategies for tissue engineering. Tissue Eng., Part B 2009, 15 (3), $353-370$.

(86) Xu, K.; Zhu, C.; Xie, J.; Li, X.; Zhang, Y.; Yao, F.; Gu, Z.; Yang, J. Enhanced vascularization of PCL porous scaffolds through VEGFFc modification. J. Mater. Chem. B 2018, 6 (27), 4474-4485.

(87) Correa do Amaral, R. J. F.; Cavanagh, B.; O’Brien, F. J.; Kearney, C. J. Platelet-derived growth factor stabilises vascularisation in collagen-glycosaminoglycan scaffolds in vitro. Journal of Tissue Engineering and Regenerative Medicine 2019, 13 (2), 261-273.

(88) Awada, H. K.; Johnson, N. R.; Wang, Y. Sequential delivery of angiogenic growth factors improves revascularization and heart function after myocardial infarction. J. Controlled Release 2015, 207, $7-17$.

(89) Chiu, L. L. Y.; Radisic, M. Scaffolds with covalently immobilized VEGF and Angiopoietin-1 for vascularization of engineered tissues. Biomaterials 2010, 31 (2), 226-241.

(90) Kim, T. H.; Kim, S. H.; Leong, K. W.; Jung, Y. Nanografted Substrata and Tri-Culture of Human Pericytes, Fibroblasts, and Endothelial Cells for Studying the Effects on Angiogenesis. Tissue Eng., Part A 2016, 22 (7-8), 698-706.

(91) Freiman, A.; Shandalov, Y.; Rozenfeld, D.; Shor, E.; Segal, S.; Ben-David, D.; Meretzki, S.; Egozi, D.; Levenberg, S. Adipose-derived endothelial and mesenchymal stem cells enhance vascular network formation on three-dimensional constructs in vitro. Stem Cell Research and Therapy 2016, 7, 5-5. 
(92) Li, M.; Ma, J.; Gao, Y.; Yang, L. Cell sheet technology: a promising strategy in regenerative medicine. Cytotherapy 2019, 21 (1), 3-16.

(93) Sakaguchi, K.; Shimizu, T.; Okano, T. Construction of threedimensional vascularized cardiac tissue with cell sheet engineering. $J$. Controlled Release 2015, 205, 83-88.

(94) Kim, J. H.; Ko, I. K.; Atala, A.; Yoo, J. J. Progressive Muscle Cell Delivery as a Solution for Volumetric Muscle Defect Repair. Sci. Rep. 2016, 6 (1), 38754.

(95) Mieszawska, A. J.; Kaplan, D. L. Smart biomaterials - regulating cell behavior through signaling molecules. BMC Biology 2010, 8, 5959.

(96) Aguirre, A.; González, A.; Navarro, M.; Castano, Ó.; Planell, J. A.; Engel, E. Control of microenvironmental cues with a smart biomaterial composite promotes endothelial progenitor cell angiogenesis. European Cells and Materials 2012, 24, 90-106.

(97) Cui, H.; Zhu, W.; Holmes, B.; Zhang, L. G. Biologically Inspired Smart Release System Based on 3D Bioprinted Perfused Scaffold for Vascularized Tissue Regeneration. Advanced science (Weinheim, Baden-Wurttemberg, Germany) 2016, 3 (8), 16000581600058.

(98) Hokugo, A.; Li, A.; Segovia, L. A.; Yalom, A.; Rezzadeh, K.; Zhou, S.; Zhang, Z.; Zuk, P. A.; Jarrahy, R. Development of Chemotactic Smart Scaffold for Use in Tissue Regeneration. Plastic and Reconstructive Surgery 2015, 135 (5), 877e-884e.

(99) Tallawi, M.; Rosellini, E.; Barbani, N.; Cascone, M. G.; Rai, R.; Saint-Pierre, G.; Boccaccini, A. R. Strategies for the chemical and biological functionalization of scaffolds for cardiac tissue engineering: a review. J. R. Soc., Interface 2015, 12 (108), 20150254-20150254.

(100) Park, H.; Temenoff, J. S.; Tabata, Y.; Caplan, A. I.; Mikos, A. $\mathrm{G}$. Injectable biodegradable hydrogel composites for rabbit marrow mesenchymal stem cell and growth factor delivery for cartilage tissue engineering. Biomaterials 2007, 28 (21), 3217-3227.

(101) Miyagi, Y.; Chiu, L. L. Y.; Cimini, M.; Weisel, R. D.; Radisic, M.; Li, R.-K. Biodegradable collagen patch with covalently immobilized VEGF for myocardial repair. Biomaterials 2011, 32 (5), $1280-1290$.

(102) Guo, H.-d.; Cui, G.-h.; Yang, J.-j.; Wang, C.; Zhu, J.; Zhang, L.-s.; Jiang, J.; Shao, S.-j. Sustained delivery of VEGF from designer self-assembling peptides improves cardiac function after myocardial infarction. Biochem. Biophys. Res. Commun. 2012, 424 (1), 105-111.

(103) Layman, H.; Sacasa, M.; Murphy, A. E.; Murphy, A. M.; Pham, S. M.; Andreopoulos, F. M. Co-delivery of FGF-2 and G-CSF from gelatin-based hydrogels as angiogenic therapy in a murine critical limb ischemic model. Acta Biomater. 2009, 5 (1), 230-239.

(104) Davis, M. E.; Hsieh, P. C. H.; Takahashi, T.; Song, Q.; Zhang, S.; Kamm, R. D.; Grodzinsky, A. J.; Anversa, P.; Lee, R. T. Local myocardial insulin-like growth factor 1 (IGF-1) delivery with biotinylated peptide nanofibers improves cell therapy for myocardial infarction. Proc. Natl. Acad. Sci. U. S. A. 2006, 103 (21), 8155-8160.

(105) Ruvinov, E.; Leor, J.; Cohen, S. The effects of controlled HGF delivery from an affinity-binding alginate biomaterial on angiogenesis and blood perfusion in a hindlimb ischemia model. Biomaterials 2010, 31 (16), 4573-4582.

(106) Kraehenbuehl, T. P.; Ferreira, L. S.; Hayward, A. M.; Nahrendorf, M.; van der Vlies, A. J.; Vasile, E.; Weissleder, R.; Langer, R.; Hubbell, J. A. Human embryonic stem cell-derived microvascular grafts for cardiac tissue preservation after myocardial infarction. Biomaterials 2011, 32 (4), 1102-1109.

(107) Lin, Y.-D.; Yeh, M.-L.; Yang, Y.-J.; Tsai, D.-C.; Chu, T.-Y.; Shih, Y.-Y.; Chang, M.-Y.; Liu, Y.-W.; Tang, A. C. L.; Chen, T.-Y.; Luo, C.-Y.; Chang, K.-C.; Chen, J.-H.; Wu, H.-L.; Hung, T.-K.; Hsieh, P. C. H. Intramyocardial Peptide Nanofiber Injection Improves Postinfarction Ventricular Remodeling and Efficacy of Bone Marrow Cell Therapy in Pigs. Circulation 2010, 122 (11), S132-S141.

(108) Kim, J. H.; Jung, Y.; Kim, S.-H.; Sun, K.; Choi, J.; Kim, H. C.; Park, Y.; Kim, S. H. The enhancement of mature vessel formation and cardiac function in infarcted hearts using dual growth factor delivery with self-assembling peptides. Biomaterials 2011, 32 (26), 60806088. 